\title{
Chemical and structural properties of reduced graphene oxide-dependence on the reducing agent
}

\author{
B. Lesiak ${ }^{1, *}$, G. Trykowski ${ }^{2, *}$, J. Tóth $^{3}$, S. Biniak ${ }^{2}$, L. Kövér ${ }^{3}$, N. Rangam ${ }^{1}$, L. Stobinski ${ }^{4,5,6}$, \\ and A. Malolepszy ${ }^{4}$ \\ ${ }^{1}$ Institute of Physical Chemistry, Polish Academy of Sciences, Kasprzaka 44/52, 01-224 Warsaw, Poland \\ ${ }^{2}$ Faculty of Chemistry, Nicolaus Copernicus University in Torun, Gagarina 7, 87-100, Torun, Poland \\ ${ }^{3}$ Section of Surface Physics, Laboratory of Materials Science, Institute for Nuclear Research, P.O. Box 51, 4001 Debrecen, Hungary \\ ${ }^{4}$ Faculty of Chemical and Process Engineering, Warsaw University of Technology, Waryńskiego 1, 00-645 Warsaw, Poland \\ ${ }^{5}$ Polski Bazalt S.A, 157 Weteranów Str., 05-250 Radzymin, Poland \\ ${ }^{6}$ NANOMATERIALS LS, 14/38 Wyszogrodzka Str., 03-337 Warsaw, Poland \\ URL: http://Www.nanomaterials.pl
}

Received: 17 May 2020

Accepted: 11 October 2020

Published online:

9 November 2020

(C) The Author(s) 2020

\begin{abstract}
Graphene oxide (GO) prepared from graphite powder using a modified Hummers method and reduced graphene oxide ( $\mathrm{rGO}$ ) obtained from GO using different reductants, i.e., sodium borohydride, hydrazine, formaldehyde, sodium hydroxide and L-ascorbic acid, were investigated using transmission electron microscopy, $\mathrm{X}$-ray diffraction, Raman, infrared and electron spectroscopic methods. The GO and rGOs' stacking nanostructure (flake) size (height $\mathrm{x}$ diameter), interlayer distance, average number of layers, distance between defects, elementary composition, content of oxygen groups, $\mathrm{C} \mathrm{sp} \mathrm{p}^{3}$ and vacancy defects were determined. Different reductants applied to GO led to modification of carbon to oxygen ratio, carbon lattice (vacancy) and $\mathrm{C} \mathrm{sp}{ }^{3}$ defects with various in-depth distribution of $\mathrm{Csp}^{3}$ due to oxygen group reduction proceeding as competing processes at different rates between interstitial layers and in planes. The reduction using sodium borohydride and hydrazine in contrary to other reductants results in a larger content of vacancy defects than in GO. The thinnest flakes rGO obtained using sodium borohydride reductant exhibits the largest content of vacancy, $\mathrm{C} \mathrm{sp}{ }^{3}$ defects and hydroxyl group accompanied by the smallest content of epoxy, carboxyl and carbonyl groups due to a mechanism of carbonyl and carboxyl group reduction to hydroxyl groups. This rGO similar diameter to GO seems to result from a predominant reduction rate between the interstitial layers. The thicker flakes of a smaller diameter than in GO are obtained in rGOs prepared using remaining reductants and result from a higher rate of reduction of in plane defects.
\end{abstract}

Handling Editor: Yaroslava Yingling.

Address correspondence to E-mail: blesiak-orlowska@ichf.edu.pl; tryki@chem.umk.pl 


\section{Introduction}

Wide varieties of methods for graphene oxide (GO) reduction have been recently utilized [1-5]. These methods include thermal, microwave, photo, chemical, electrochemical and solvothermal reduction. The most commonly applied chemical reduction routes use a wide variety of chemical compounds. Strong reducing agents are hydrazine and its derivatives (hydrazine hydrate and dimethylhydrazine), metal hydrides (sodium hydride, sodium borohydride), hydroiodic acid, etc. Other, weak reducing agents include ascorbic acid, hydroquinone, pyrogallol, hot strong alkaline solutions $(\mathrm{KOH}, \mathrm{NaOH})$, hydroxylamine and urea [1 and references included]. Reduction procedures of GO using different conditions, i.e. vapor, aqueous solutions of different concentrations and time, result in preparation of reduced graphene oxide $(\mathrm{rGO})$ of variety of chemical and structural properties.

The main criteria for estimating the effect of reduction are $\mathrm{C} / \mathrm{O}$ ratio, optical properties, structural defects and electrical conductivity. The electrical conductivity of a monolayer graphene depends on the carrier transport and therefore rGO chemical properties, where the oxygen groups attached to the charge carrying plane are more important in contrary to oxygen groups attached to the edges of the charge carrying planes. Reduction of chemically prepared GO results in rGO arranged in graphene stacking nanostructures (flakes) of various average height and diameter with graphene interlayers separated by a distance depending on the degree of the reduction, which implicates the average number of layers in graphene flakes [5]. Therefore, the conductivity of rGO depends not only on $\mathrm{C} / \mathrm{O}$ ratios, the number of still existing in rGO different oxygen groups and their ratios, but also on structural properties of the obtained rGO flakes and layers like size of flakes, type and content of defects in graphene layers.

Description of structural and chemical properties of graphene materials basing on results obtained using X-ray photoelectron spectroscopy (XPS), X-ray excited Auger electron spectroscopy (XAES), reflection electron energy loss spectroscopy (REELS), Raman spectroscopy, X-ray diffraction (XRD), transmission electron microscopy (TEM), Fourier transformed infrared spectroscopy (FTIR), atomic force microscopy (AFM), etc., has been often reported
[1-19]. The FTIR and XPS analyses are usually applied for probing the chemical properties of atoms, carbon hybridizations and oxygen groups, where FTIR analysis information is related to the bulk, and XPS information depth is limited to the surface, i.e. few nanometers. By the recently developed complementary approaches of Raman spectroscopy [8-19] of few micrometers information depth, the surface AFM [8] and REELS [5] methods provide the information on the structural and chemical properties like level of disorder, dopants, the number of layers, the linear dispersion of electronic energy, the crystal orientation, the defects and strain [8-19].

Although, numerous procedures of reduction of GO using various reducing agents have been proposed [1 and references within], there are still many points to clarify like how oxygen groups are reduced, how lattice defects are being formed and reconstructed and what are the mechanisms of reduction and carbon lattice reconstruction using various chemical preparations and compounds. An attempt to reveal these differences was made using FTIR, Raman and surface XPS, XAES and REELS studies utilizing different in-depth sensitivity. The particular aim of the present work was to obtain information on differences in effectivity of the chemical reduction of GO flakes performed in aqueous solutions of various chemical compounds, i.e. strong and weak reductants like sodium borohydride $\left(\mathrm{NaBH}_{4}\right)$, hydrazine $\left(\mathrm{N}_{2} \mathrm{H}_{4}\right)$, formaldehyde $\left(\mathrm{CH}_{2} \mathrm{O}\right)$, sodium hydroxide $(\mathrm{NaOH})$, L-ascorbic acid $\left(\mathrm{C}_{6} \mathrm{H}_{8} \mathrm{O}_{6}\right)$, as well as $\mathrm{L}$-ascorbic acid $\left(\mathrm{C}_{6} \mathrm{H}_{8} \mathrm{O}_{6}\right)$ prepared at room temperature (RT). The study presents the detailed comparison of the structural and chemical properties of the reduced GO samples, however is not concerned with investigating the kinetics of the reduction reaction.

\section{Information depth of electron spectroscopic methods}

A convenient measure of surface sensitivity in electron spectroscopic methods (XPS, XAES, REELS) is the information depth, $I D$, defined as the maximum depth, normal to the surface, from which useful signal information of a specified percentage, $P$, of signal originates $[20,21]$. Therefore, ID can describe the sampling depth of this specified percentage of signal. The averaged information depth called a mean escape depth, MED, in XPS and XAES and mean 
penetration depth, MPD, in REELS is defined as an average depth normal to the surface from which the specified particles escape [22, 23]. Assuming single scattering of electrons, these values can be evaluated from the equations given as follows [20, 21].

$$
\begin{aligned}
I D(P)_{X P S} & =\lambda \cos \alpha_{\text {out }} \ln \left(\frac{1}{1-P / 100}\right), I D(P)_{\text {REELS }} \\
& =\lambda \frac{\cos \alpha_{\text {in }} \cos \alpha_{\text {out }}}{\cos \alpha_{\text {in }}+\cos \alpha_{\text {out }}} \ln \left(\frac{1}{1-P / 100}\right), \\
M E D_{X P S} & =\lambda \cos \alpha_{\text {out }}, M P D_{\text {REELS }}=\lambda \frac{\cos \alpha_{\text {in }} \cos \alpha_{\text {out }}}{\cos \alpha_{\text {in }}+\cos \alpha_{\text {out }}}
\end{aligned}
$$

where $\lambda$ is the inelastic mean free path, IMFP, of electrons scattered inelastically dependent on the kinetic energy, $\mathrm{KE}$, of the electrons and on the material, $\cos \alpha_{\text {in }}$ and $\cos \alpha_{\text {out }}$ are angles of incidence and emission of electrons with respect to the surface normal of the specimen and $P$ is a specified percentage of the signal considered. The values of $I D(P=99 \%), M E D, M P D$ for the applied geometry of analysis and values of IMFPs in graphite published by Shinotsuka et al. [24] evaluated for the investigated transitions are listed in Table 1. The considered theoretical values of IMFPs [24] are in agreement with the experimentally determined values of IMFPs for bi-, tri- and multilayer graphene as found by $\mathrm{Xu}$ et al. [25].

The in-depth profile of graphene layers from REELS spectra is evaluated using an exponential interpolation of intensity of reflected inelastically scattered electrons, where the signal can be attenuated according to equation [26]:

$I=I^{\infty}\left(1-\exp \left(-z / l \cos a_{\text {out }}\right)\right.$,

where $I$ is the signal intensity from the overlayer of thickness $z, I^{\infty}$ is the signal intensity from the overlayer material of infinite thickness [5], $\lambda$ is the IMFP [24] and $\alpha_{\text {out }}$ is the electron emission angle with respect to the surface normal.

\section{Experimental}

\section{Sample preparation}

The following samples were investigated: a commercially available graphite (denoted as Gr) of $99.0 \%$ purity (AcrosOrganics, USA, 325 mesh) and expanded graphite (denoted as Gr-exp), graphene oxide (denoted as GO) and reduced graphite oxide samples prepared from GO using different reductants, i.e. sodium borohydride $\left(\mathrm{NaBH}_{4}\right)$, hydrazine $\left(\mathrm{N}_{2} \mathrm{H}_{4}\right)$ [5], sodium hydroxide $(\mathrm{NaOH})$, formaldehyde $\left(\mathrm{CH}_{2} \mathrm{O}\right)$ and L-ascorbic acid $\left(\mathrm{C}_{6} \mathrm{H}_{8} \mathrm{O}_{6}\right)$. These reduced graphene oxide samples were denoted as rGO-NaBH ${ }_{4}, \mathrm{rGO}_{-} \mathrm{N}_{2} \mathrm{H}_{4}, \mathrm{rGO}-\mathrm{NaOH}, \mathrm{rGO}-\mathrm{CH}_{2} \mathrm{O}$ and rGO- $\mathrm{C}_{6} \mathrm{H}_{8} \mathrm{O}_{6}$.

The GO sample was prepared from commercially available graphite using a modified Hummers method [27]. The reduction using $\mathrm{NaBH}_{4}, \mathrm{NaOH}$, $\mathrm{C}_{6} \mathrm{H}_{8} \mathrm{O}_{6}$ and $\mathrm{CH}_{2} \mathrm{O}$ reductants proceeded in $100 \mathrm{ml}$ water suspension of GO $(0.6 \mathrm{wt} . \%)$ mixed with $50 \mathrm{ml}$ $1 \mathrm{M}$ water solution of $\mathrm{NaBH}_{4}, \mathrm{NaOH}, \mathrm{C}_{6} \mathrm{H}_{8} \mathrm{O}_{6}$ reducing agents, whereas reduction of $\mathrm{GO}$ using $\mathrm{N}_{2} \mathrm{H}_{4}$ proceeded using $50 \mathrm{ml}$ of $50 \%$ solution of hydrazine hydrate. The GO and reducing agent solutions were boiled under a reflux for $30 \mathrm{~min}$. Then, all the reaction mixtures were cooled to RT, washed in deionized water till the $\mathrm{pH}$ of filtrate stabilized to ca. 7-8, and then they were dried. Additional reduction procedure using L-ascorbic acid $\left(\mathrm{C}_{6} \mathrm{H}_{8} \mathrm{O}_{6}\right)$ at $\mathrm{RT}$ was proceeded under stirring of $\mathrm{GO}$ and $\mathrm{C}_{6} \mathrm{H}_{8} \mathrm{O}_{6}$ in water solution for $30 \mathrm{~min}$ and then washing in deionized water till $\mathrm{pH}$ filtrate stabilized to ca. 7-8 and drying.

\section{HR-TEM, EDX, PEELS and XRD apparatus}

A high resolution transmission electron microscope (HR-TEM), Tecnai 20F X-Twin, equipped with an electron source, a cathode with field emission gun (FEG), EHT $=200 \mathrm{keV}$, a camera Orius and a highangle annular dark-field (HAADF) detector, was used. This TEM was equipped with energy-dispersive X-ray spectrometer (EDX) with the energy resolution of $134 \mathrm{eV}$ (EDAX RTEM SN9577+) and parallel electron energy loss spectrometer (PEELS) with the energy resolution of $0.8 \mathrm{eV}$. The quantification was performed according to the modified standardless/ thin foil method. The preparation of samples proceeded in the following steps: sonication for $5 \mathrm{~s}$ of a few milligrams of sample in ethanol $(99.8 \%$ anhydrous) using ultrasounds, applying a drop of the solution of $5 \mu \mathrm{l}$ on a carbon coated copper mesh with holes (Lacey type $\mathrm{Cu} 400$ mesh, Plano), evaporating the solvent at room temperature and then investigating the remaining dried powder stuck on the copper mesh. 
Table 1 The $M E D, M P D$ and $(I D(P=99 \%)$ ) (Eq. (1)) of the investigated signal evaluated using the IMFPs, $\lambda$, in carbon from Shinotsuka [24] and a number of layers evaluated assuming an

\begin{tabular}{|c|c|c|c|c|c|c|}
\hline \multirow[t]{2}{*}{ Spectrum } & \multirow[t]{2}{*}{$\mathrm{KE}(\mathrm{eV})$} & \multirow[t]{2}{*}{ IMFP (nm) } & \multirow[t]{2}{*}{$I D(99 \%)-M E D / M P D(\mathrm{~nm})$} & \multicolumn{3}{|c|}{ Number of layers $(I D-M E D / M P D)$} \\
\hline & & & & GO & rGO & graphite \\
\hline REELS-bulk & 4000 & 5.55 & $10.0-2.17$ & $14-3$ & $25-5$ & $30-7$ \\
\hline REELS-bulk & 2000 & 3.15 & $6.53-1.42$ & $9-2$ & $16-4$ & $20-4$ \\
\hline C 1 s XPS EELS & 1202 & 2.11 & $9.72-2.11$ & $14-3$ & $24-5$ & $29-6$ \\
\hline C KLL & 272 & 0.72 & $3.32-0.72$ & $5-1$ & $8-2$ & $10-2$ \\
\hline
\end{tabular}

interlayer distance in GO of $0.721 \mathrm{~nm}$, rGOs of $0.4 \mathrm{~nm}$ and graphite of $0.335 \mathrm{~nm}$
Powder X-ray diffraction (pXRD) patterns were obtained by using an X'Pert Pro diffractometer, with $\mathrm{Cu} \mathrm{K} \alpha$ radiation $(\lambda=1.5406 \AA)$ and with a $\mathrm{X}^{\prime}$ Celerator detector.

\section{Raman apparatus}

A Raman micro-spectrometer, Senterra, Bruker Optik with a $532 \mathrm{~nm}$ laser was used. The measurement parameters are the following: laser power of $2 \mathrm{~mW}$, acquisition time of $360 \mathrm{~s}$, number of scans 2 and analyzed range of $800-3000 \mathrm{~cm}^{-1}$.

\section{FTIR apparatus}

The FTIR spectra in the $70-4000 \mathrm{~cm}^{-1}$ range were recorded in vacuum spectrometer with Fourier transformation, Vertex $70 \mathrm{~V}$, Bruker Optik, at $T=22{ }^{\circ} \mathrm{C}, p=10^{-1} \mathrm{~Pa}$, resolution $4 \mathrm{~cm}^{-1}$ and number of scans 100. Before the sample measurement, a "vacuum spectrum" was recorded and subtracted automatically as background during registration of spectra for the investigated samples. The sample was mixed with $\mathrm{KBr}$ at a ratio of $1 / 300 \mathrm{mg}$ and then compressed at $7 \mathrm{MPa} \mathrm{cm}{ }^{-2}$ to form a pellet, and the transmission spectrum was recorded in the range of $750-1900 \mathrm{~cm}^{-1}$.

\section{XPS apparatus}

The XPS measurements were carried out in an ultrahigh-vacuum (UHV) using the ESA-31 electron spectrometer (homemade) [28]. The spectrometer is equipped with a hemispherical electron energy analyzer of a high relative energy resolution of $0.5 \%$ without retardation (the retarding ratio, $k$, can be changed from 2 to 100), an electron gun (LEG62-VG
Microtech), a homemade X-ray excitation source (Al $\mathrm{K} \alpha \mathrm{X}$-rays $\mathrm{h} v=1486.67 \mathrm{eV}$ ) and an $\mathrm{Ar}^{+}$ion source of AG21 (VG Scientific). The XPS spectra were measured in the fixed retarding ratio (FRR) mode $(k=4$, $8,16)$ at a photon incidence and electron emission angles of $70^{\circ}$ and $0^{\circ}$, respectively, with respect to the surface normal of the specimen. The REELS spectra were measured using a primary electron energy of $4 \mathrm{keV}$ ( $k=41$, generally keeping the analyzer pass energy at about $50-100 \mathrm{eV}$ ) and the electron beam current intensity of a few $\mathrm{nA}$ at electron incidence and emission angles of $50^{\circ}$ and $0^{\circ}$ with respect to the surface normal of the specimen, respectively.

The prepared powder of graphite, $\mathrm{GO}$ and rGO samples was placed on a holder using an UHV tape and investigated without any thermal and/or chemical pretreatment.

\section{Results and discussion}

\section{Structural properties of graphene flakes by HR-TEM, EDX and PEELS}

The EDX spectra of exemplary rGO-NaBH${ }_{4}$ and rGO$\mathrm{CH}_{2} \mathrm{O}$ samples (Fig. S1) reveal in the bulk the presence of $\mathrm{C}, \mathrm{O}$ and Na. The PEELS spectra show differences in the intensity of elastic peak and inelastic loss peaks in the energy loss region of about $50-400 \mathrm{eV}$, as well as inelastic energy loss values indicating structural variations between the presented samples.

The TEM images of exemplary rGOs (Fig. 1) show transparent parts confirming graphene layers structure with dark parts due to the overlapping layers. 


\section{Graphene interlayer distance and size of flakes by XRD}

The XRD (002) and (10) patterns of the investigated samples (Fig. 2) were fitted using Pearson7 function (Fig. S2). The resulting fitting parameters, i.e. Bragg's angle of (002) and (10) patterns and the respective full-width at half maximum (FWHM) values, are listed in Table S1. The structural parameters, i.e. the average interlayer distance, $d$, height of the stacking nanostructures, $H$, number of layers in the flakes, $n$, and diameter of the flakes, $D$, evaluated using Bragg's and Scherrer's equations are listed in Table 2. For evaluating the value of $H$ from (002) pattern and $D$ from (10) pattern, the constants of 0.9 and 1.84 were considered, respectively.

The structural parameters of GO, rGOs vary depending on the reductant (Table 2). The interlayer distance is $0.721 \mathrm{~nm} \quad(\mathrm{GO})$ and $0.446-0.345 \mathrm{~nm}$ (rGOs). These values confirmed elsewhere, i.e. $0.335 \mathrm{~nm}$ (graphite), $0.335-0.4 \mathrm{~nm} \quad(\mathrm{rGO})$ and $0.77-0.9 \mathrm{~nm}$ (GO) increase with humidity [5, 29-31]. The rGO reduced using $\mathrm{NaBH}_{4}$ shows considerably large flake diameter of the smallest thickness and average number of graphene layers. These average number of layers in different $\mathrm{rGO}$ flakes increases in the following order: $\mathrm{rGO}-\mathrm{NaBH}_{4}<\mathrm{rGO}-\mathrm{N}_{2} \mathrm{H}_{4}$ $<$ rGO- $\mathrm{C}_{6} \mathrm{H}_{8} \mathrm{O}_{6}-\mathrm{RT}<$ rGO- $\mathrm{C}_{6} \mathrm{H}_{8} \mathrm{O}_{6}<\mathrm{rGO}-\mathrm{CH}_{2-}$ $\mathrm{O}<\mathrm{rGO}-\mathrm{NaOH}$.

\section{Structural properties of graphene flakes by Raman spectroscopy}

The Raman spectrum is considered to depend on: (i) clustering of the $\mathrm{sp}^{2}$ phase, (ii) bond disorder, (iii) the presence of $\mathrm{sp}^{2}$ rings or chains and (iv) the $\mathrm{sp}^{2} / \mathrm{sp}^{3}$ ratio, where these factors act as competing forces influencing the shape of the Raman spectra. Classification according to these features was proposed by Ferrari and Robertson [12] as an amorphization trajectory consisting of three stages ranging from graphite to tetrahedral amorphous carbon (ta-C) or defected diamond, i.e. (1) graphite to nanocrystalline graphite (nc-Gr), (2) nanocrystalline graphite to amorphous carbon (a-C) and (3) a-C to $100 \% \mathrm{sp}^{3}$ ta-C or defected diamond. The classification and interpretation of the Raman spectra require consideration of intensity and width (FWHM) of the Raman modes. The main features of Raman spectra of graphene show characteristic major bands assigned to the first- order $D\left(\sim 1320-1350 \mathrm{~cm}^{-1}\right), G\left(\sim 1570-1605 \mathrm{~cm}^{-1}\right)$, $D^{\prime}\left(\sim 1620 \mathrm{~cm}^{-1}\right), D+D^{\prime}\left(\sim 2900 \mathrm{~cm}^{-1}\right)$ modes and the second-order $2 D$ mode (2640- $2680 \mathrm{~cm}^{-1}$ ) (Fig. 3). The $D$ mode is an in-plane breathing vibration of the six-membered carbon rings and is considered as a disorder-induced band. Therefore, the $D$ band reflects defects like destroyed carbon hexagons, and it is not present for a perfect graphite structure in contrary to amorphous structures, for which its intensity is high. The intensity and FWHM of $D$ band depend on disorder and the type of edges, where the intensity is higher for armchair than for zigzag edges. The $G$ mode is due to the in-plane stretching vibration of carbon atom pairs and is observed for all carbon structures containing $\mathrm{sp}^{2}$ bonds, both aromatic carbon and other $\mathrm{sp}^{2}$ structures. The $2 D$ allowed mode is the most intense for an ideal singlelayer graphene. A low intensity $D$ band accompanied by a presence of $2 D$ band indicates a high-quality graphene. The main features of the evolution of Raman spectrum in stage 1 are appearance of $D$ mode, increasing of $I(D) / I(G)$ ratio following Tuinstra and Koenig (TK) relations [13], appearance of $D^{\prime}$ mode, disappearance of $D$ and $2 D$ mode doublet structure, appearance of $D+D^{\prime}$ mode and at the end of stage 1 , overlapping of $G$ and $D^{\prime}$ modes. The ratio of intensity of $D$ to $G$ mode is inversely proportional to the size of effective crystallite size in the direction of the graphite plane, $L_{a}$, or graphitic cluster, i.e.:

$I(D) / I(G)=C(\lambda) / L_{a}$

where $\lambda$ is Raman wavelength and $C(515.5 \mathrm{~nm})=$ $4.4 \mathrm{~nm}$ [12]. In the stage 2, the position of $G$ mode decreases, the TK relations fails and $I(D) / I(G)$ decreases. The broad feature from about $2300 \mathrm{~cm}^{-1}$ to $3200 \mathrm{~cm}^{-1}$ modulated by $2 D, D+D^{\prime}$ and $2 D^{\prime}$ modes appears instead of a well-defined second-order peaks. For stage 2, the new relation was proposed by Ferrari and Robertson [12]:

$I(D) / I(G)=C^{\prime}(\lambda) L_{a}^{2}$

with $C^{\prime}(514) \sim 0.55 \mathrm{~nm}^{-2}$.

The stage 3 is beyond the data presented and therefore is omitted in discussion.

In all stages of amorphization trajectory, the structural defects exist lowering the symmetry of the infinite crystal and they include: (i) the point-like defects, (ii) cluster defects and (iii) boundary or edge defects. The experimental investigation of defects [17] in Ar bombarded graphene and graphite with 
Figure 1 The HR-TEM images of a rGO-NaBH$H_{4}$ and b $\mathrm{rGO}-\mathrm{CH}_{2} \mathrm{O}$. (a)
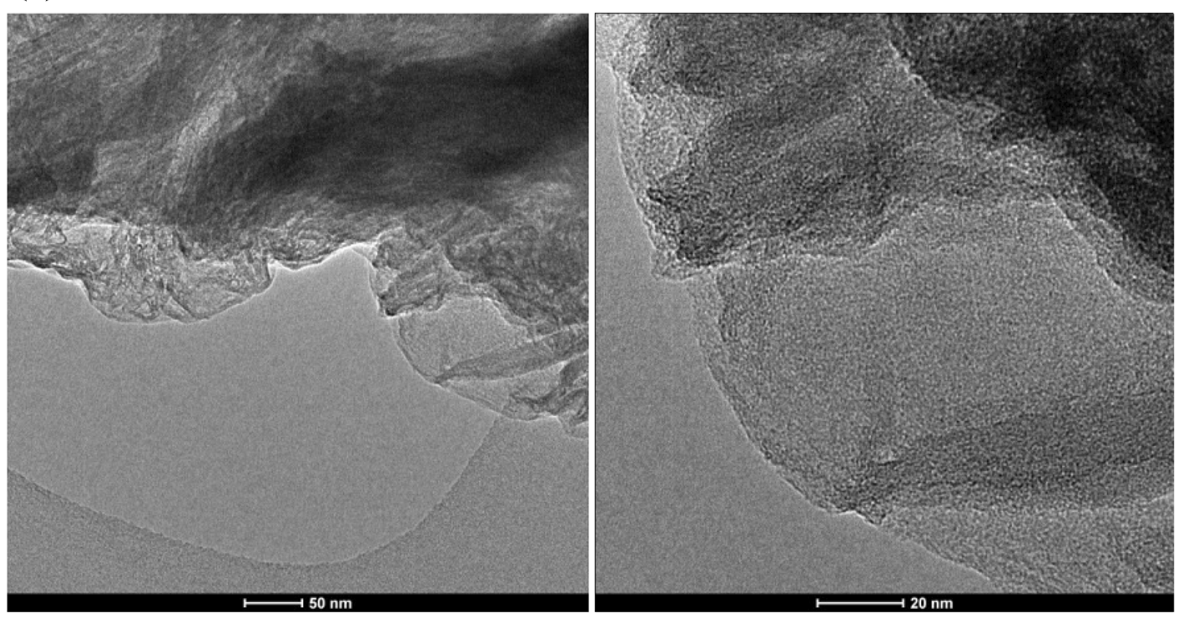

(b)
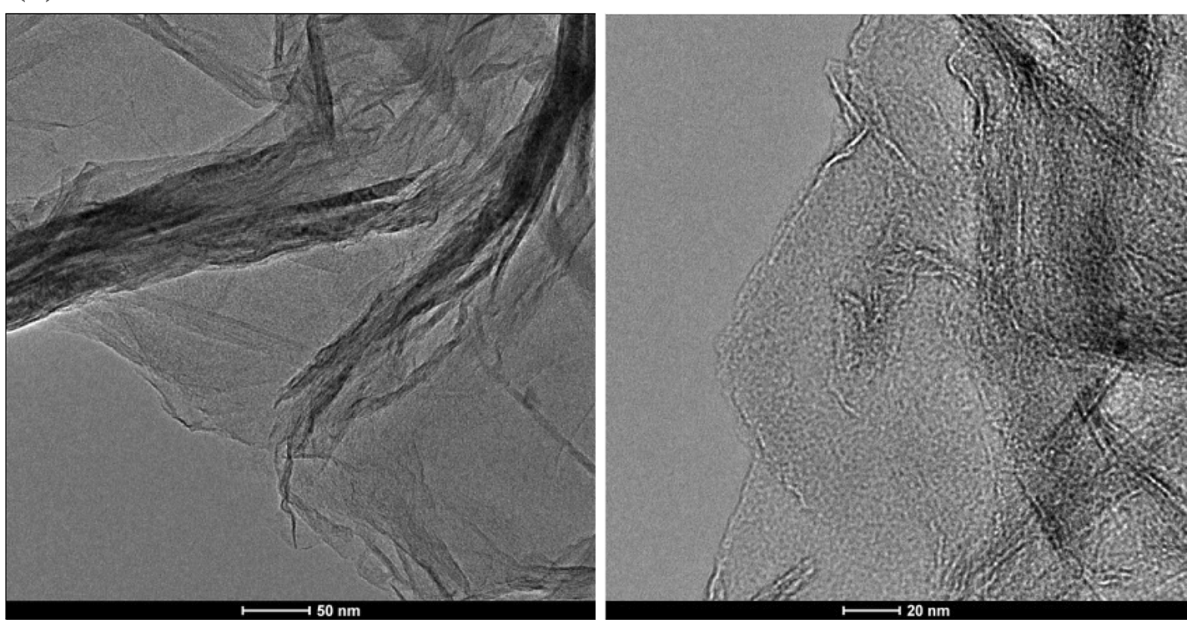

different grain size like: (i) vacancy defects produced by the deformation of the carbon lattice bond, (ii) onsite defects, which describe out-of-plane atoms bonded to carbon atoms (namely $\mathrm{sp}^{3}$ hybridization) and (iii) boundary or edge defects, provided detectable $D$ and $D^{\prime}$ modes modification. The experimental data showed that $I(D) / \mathrm{I}\left(D^{\prime}\right)$ is maximum ( 13) for defects associated with $\mathrm{sp}^{3}$ hybridization, it decreases for vacancy-like defects $(\sim 7)$ and reaches a minimum for boundary-like defects in graphite ( 3.5) [17]. Other work by Lucchese et al. [18] studying disorder and defects in graphene caused by Ar ion bombardment provided quantification of defects, i.e. the average distance between point-like defects, $L_{D}$, and density of defects, $n_{D}\left(L_{D} \sim\right.$ $1 / \sqrt{n_{D}}$ ) by fitting the observed $I(D) / I(G)$ versus $L_{D}$ using a phenomenological model. The values of $I(D) /$ $I(G)$ have a non-monotonic dependence on $L_{D}$, increasing with increasing $L_{D}$ up to $L_{D} \sim 4 \mathrm{~nm}$ in stage 2, and then decreasing for $L_{D}>4 \mathrm{~nm}$ (stage 1) and being in agreement with a well-established graphitization trajectory for carbon materials proposed by Ferrari and Robertson [12]. Such behavior suggests the existence of two disorder-induced competing mechanisms contributing to the Raman $D$ band. The phenomenological model considers that the impact of a single ion in the graphene sheet causing modifications on two length scales, here denoted by $r_{\mathrm{A}}$ and $r_{\mathrm{S}}$ (with $r_{\mathrm{A}}>r_{\mathrm{S}}$ ), which are the radii of two circular areas measured from the impact point and subscript $A$ stands for "activated," whereas the subscript $S$ stands for "structurally-defective," with values of $r_{S}=1 \mathrm{~nm}$ and $r_{A}=3 \mathrm{~nm}$ [19]. This model extended by Concado et al. [19] to other Raman lines is valid for $L_{D}>10$, i.e. for a low-density defects materials.

The measured shapes, positions, relative intensities of $D, G, 2 D, D+D^{\prime}$ modes and FWHM of Raman 
spectra are characteristic for carbon materials (Fig. 3, Table 3, Fig. S3-S5). According to the above, both graphite samples can be classified to stage 1 , whereas GO and rGOs to stage 2 . The values of $L_{a}$ evaluated
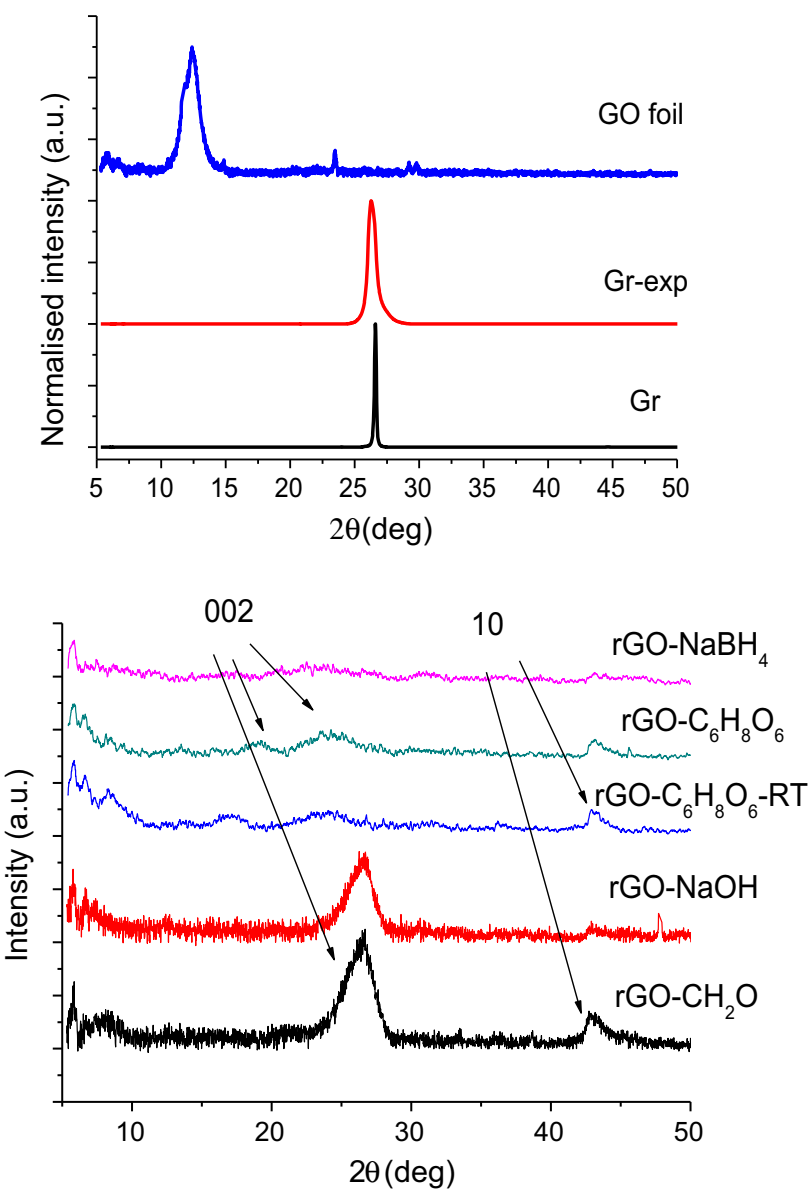

Figure 2 The XRD diffractograms recorded from the investigated samples.

Table 2 Comparison of structural parameters of GOs and rGOs from XRD patterns. Symbols denote: $d$-average distance between graphene layers, $H$-average height of flakes, $n$-average number of graphene layers and $D$-average diameter of flakes according to Eqs. (3) are listed in Table 3. Therefore, graphite samples exhibit a low defect density, whereas GO and rGO exhibit a high defect density. The stage $1 \mathrm{Gr}$ and Gr-exp samples show spectra of a high intensity and small FWHM of $G$ mode indicating dominating graphite structure of low defect density. These samples are characterized by the

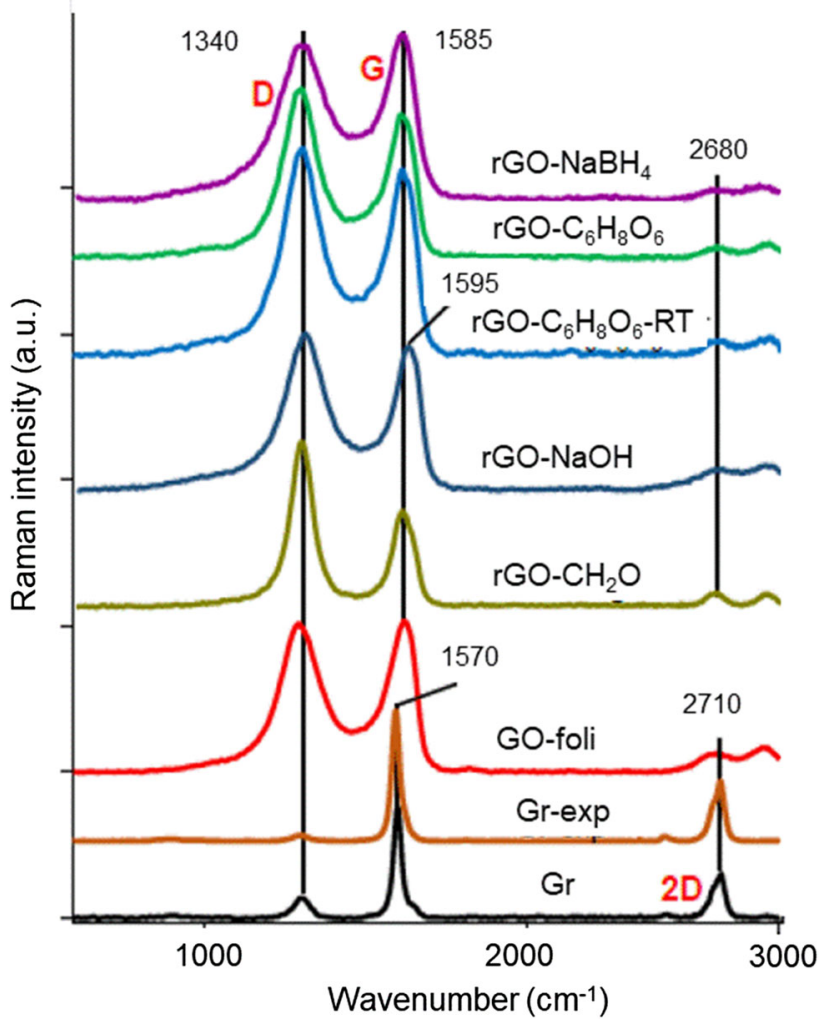

Figure 3 The Raman spectra recorded from the investigated samples.

\begin{tabular}{|c|c|c|c|c|}
\hline \multirow[t]{2}{*}{ Sample } & \multicolumn{3}{|l|}{ Peak (002) } & \multirow{2}{*}{$\begin{array}{l}\text { Peak (10) } \\
\text { Average } D(\mathrm{~nm})\end{array}$} \\
\hline & Average $d(\mathrm{~nm})$ & Average $H(\mathrm{~nm})$ & Average $n(\mathrm{~nm})$ & \\
\hline GO-foil & 0.721 & 4.883 & 6.8 & *22 \\
\hline rGO-NaBH ${ }_{4}$ & 0.388 & 0.549 & 1.4 & 22 \\
\hline$* \mathrm{rGO}-\mathrm{N}_{2} \mathrm{H}_{4}$ & 0.383 & 1.302 & 3.4 & 8 \\
\hline rGO- $\mathrm{C}_{6} \mathrm{H}_{8} \mathrm{O}_{6}-\mathrm{RT}$ & 0.446 & 2.010 & 4.5 & 22 \\
\hline rGO- $\mathrm{C}_{6} \mathrm{H}_{8} \mathrm{O}_{6}$ & 0.408 & 1.903 & 4.7 & 11 \\
\hline $\mathrm{rGO}-\mathrm{CH}_{2} \mathrm{O}$ & 0.350 & 4.099 & 11.7 & 11 \\
\hline rGO-NaOH & 0.345 & 4.990 & 14.4 & 14 \\
\hline $\mathrm{Gr}$ & 0.344 & - & - & - \\
\hline Gr-exp & 0.347 & - & - & - \\
\hline
\end{tabular}

The value of $n$ is evaluated according to the formula: $n=H / d$

*From Ref. [5] 
smallest ratio of $I(D) / I(G)$ (Table 3) at maximum of G mode at $1572-1575 \mathrm{~cm}^{-1}$. The stage 2 of amorphization trajectory includes GO and rGO samples, which characteristic features are high intensities and width of FWHM of $D$ and $G$ modes, very weak intensity of $2 D$ mode and values of $I(D) / I(G)$ close to 1 . The variation of positions and FWHM of $D, G$ and $2 D$ modes (Fig. S3-S5) confirms that the investigated samples have different thickness, $\mathrm{C} \mathrm{sp}^{3}$ content, graphitic clusters size, distance between defects and their density (Fig. S5), crystallinity (Fig. S4, Table 3) [8-19]. The FWHM and intensity values of $D$ and $G$ mode indicate the distance between point-like defects smaller than $3 \mathrm{~nm}$ [19], for which phenomenological evaluation of distance between defects proposed by Concado et al. [19] is not valid. The rGOs exhibit higher crystallinity than GO, whereas the highest crystallinity is shown by graphite and expanded graphite (Fig. S4). As reported elsewhere for rGOs [12], increasing frequency of $D$ band position and decreasing frequency of $G$ band position accompanied by decreasing FWHM of $D$ and $G$ bands (Fig. S3) is related to decreasing $\mathrm{C} \mathrm{sp}{ }^{3}$ content and increasing $L_{a}$. While increasing $L_{a}$ value provides decreasing position and FWHM of $2 D$ mode [20], the increasing number of layers leads to an opposite effect [10]. Therefore, the $2 D$ band in Raman spectra exhibits these two effects (Fig. S3).

\section{Chemical groups in graphene flakes by FTIR spectroscopy}

The FTIR measurement procedures (transmittance of $\mathrm{KBr}$ pellets) do not provide quantitative determination of surface (or volumetric) concentration of chemical moieties (Fig. 4). The comparison of band intensity for various samples cannot provide clear information about their chemical structure because of the arbitrary background subtraction and band extension. A stoichiometric structure of GO, heterogeneity of the oxygenated functional groups and their interaction lead to overlapping of the characteristic bands and affect their position and intensity. However, the recorded spectra indicate: (i) the presence (or absence) of the chemical structures and (ii) changes in relative intensities of the respective bands caused by reduction procedures informing on chemical structures transformation.

In all FTIR spectra (Fig. 4), two main range of absorption bands $1750-1450 \mathrm{~cm}^{-1}$ and
1300-950 $\mathrm{cm}^{-1}$ characteristic for $\mathrm{C}=\mathrm{O}$ and $\mathrm{C}-\mathrm{O}$ moieties, respectively, can be noticed [6,7]. The left side of the spectra starts with more or less shaped band near $1720 \mathrm{~cm}^{-1}$ attributed to the stretching vibration of $\mathrm{C}=\mathrm{O}$ moiety in carboxylic (conjugated and/or non-conjugated) or carbonate systems (acid, ester, anhydride, dioxolan). The bands at $1635 \mathrm{~cm}^{-1}$ and $1565 \mathrm{~cm}^{-1}$ can be assigned to aromatic carboncarbon bonds, carbonyl moieties in various chemical surroundings (quinone-, ketone-, aldehyde-like, amide-like), carbon-oxygen ion-radical structures and conjugated systems (diketone, keto-esters, ketoenol and quinone-hydroquinone structures). The adsorbed/intercalated water provides deformation vibration band $\delta(\mathrm{HOH})$ located near $1630 \mathrm{~cm}^{-1}$ overlapping with $\mathrm{C}-\mathrm{OH}$ mode at $1620 \mathrm{~cm}^{-1}$. The next set of the overlapping peaks, which form an absorption band in $1300-950 \mathrm{~cm}^{-1}$ region, can be attributed to $\mathrm{C}-\mathrm{O}$ moieties existing in a different structural environment. In this spectral region, the presence of $\mathrm{C}-\mathrm{O}-\mathrm{C}$ symmetric stretching vibration bands in ether-, ester- lactone-, pyrone-, furane-like structures should be taken into consideration. Also, phenol and hydroxyl molecular groups exhibit characteristic mode located near $1070 \mathrm{~cm}^{-1}$ (C-OH vibration), while the epoxide group provides a mode near $1290 \mathrm{~cm}^{-1}$ (asymmetric C-O-C stretching).

The graphite (Gr) spectrum was arbitrary extended and small amount of oxygen bonded with carbon in the form of carboxylic and ether groups, as well as strongly adsorbed water can be observed. The peak assigned to in-plane stretching of aromatic rings $(v(C=C))$ with frequency $1580 \mathrm{~cm}^{-1}$ is visible (only partially overlapped). The oxidative treatment of graphite (GO samples) gives large enhancement of $\mathrm{C}=\mathrm{O}$ and $\mathrm{C}-\mathrm{O}$ bands described by the above mentioned oxygen-containing functional groups-the increase in relative intensity of these peaks and covering the aromatic peaks can be observed. The difference in the shape of the spectra recorded for Grexp and GO-foil-markedly the increase in relative intensity of the band in $\mathrm{C}-\mathrm{O}-\mathrm{C}$ region (near $1200 \mathrm{~cm}^{-1}$ ) — can be explained by stronger dehydration of GO-foil with creation of anhydride structures (lactone). The GO reduction using different procedures modifies the FTIR spectra. After reduction with sodium hydroxide in $\mathrm{rGO}-\mathrm{NaOH}$, a relative decrease in the peak ascribed to carboxylic moieties $\left(1720 \mathrm{~cm}^{-1}\right)$ and a relative increase of the band associated with the presence of hydroxyl groups 
Table 3 The parameters of $D, G$ and $2 D$ bands of Raman spectra and the effective crystallite size in the direction of the graphite plane, $L_{a}$, for the investigated samples

\begin{tabular}{|c|c|c|c|c|c|c|c|c|c|}
\hline \multirow[t]{2}{*}{ Sample } & \multicolumn{2}{|l|}{$D$ band } & \multicolumn{2}{|l|}{$G$ band } & \multicolumn{2}{|c|}{$2 D$ band } & \multirow{2}{*}{$\begin{array}{l}I(D) / \\
I(G)\end{array}$} & \multirow{2}{*}{$\begin{array}{l}I(2 D) / \\
I(G)\end{array}$} & \multirow[t]{2}{*}{$L_{a}(\mathrm{~nm})$} \\
\hline & $\begin{array}{l}\text { Pos. } \\
\left(\mathrm{cm}^{-1}\right)\end{array}$ & $\begin{array}{l}\text { FWHM } \\
\left(\mathrm{cm}^{-1}\right)\end{array}$ & $\begin{array}{l}\text { Pos. } \\
\left(\mathrm{cm}^{-1}\right)\end{array}$ & $\begin{array}{l}\text { FWHM } \\
\left(\mathrm{cm}^{-1}\right)\end{array}$ & $\begin{array}{l}\text { Pos. } \\
\left(\mathrm{cm}^{-1}\right)\end{array}$ & $\begin{array}{l}\text { FWHM } \\
\left(\mathrm{cm}^{-1}\right)\end{array}$ & & & \\
\hline GO-foil & 1337 & 119 & 1594 & 82 & 2687 & 243 & 0.991 & 0.4650 & 1.34 \\
\hline rGO-NaBH 4 & 1343 & 148 & 1587 & 97 & 2701 & 229 & 0.980 & 0.8422 & 1.34 \\
\hline $\begin{array}{l}\text { rGO- } \mathrm{C}_{6} \mathrm{H}_{8} \mathrm{O}_{6^{-}} \\
\mathrm{RT}\end{array}$ & 1342 & 110 & 1585 & 73 & 2691 & 206 & 1.017 & 0.7831 & 1.36 \\
\hline rGO- $\mathrm{C}_{6} \mathrm{H}_{8} \mathrm{O}_{6}$ & 1341 & 100 & 1585 & 79 & 2689 & 152 & 1.028 & 0.8410 & 1.37 \\
\hline $\mathrm{rGO}-\mathrm{CH}_{2} \mathrm{O}$ & 1342 & 60 & 1585 & 68 & 2687 & 93 & 1.242 & 0.7210 & 1.5 \\
\hline $\mathrm{rGO}-\mathrm{NaOH}$ & 1340 & 65 & 1583 & 61 & 2683 & 101 & 1.133 & 0.8097 & 1.44 \\
\hline $\mathrm{Gr}$ & 1342 & 45 & 1572 & 24 & 2710 & 72 & 0.214 & 0.4315 & 20.56 \\
\hline Gr-exp & 1345 & 42 & 1575 & 24 & 2712 & 67 & 0.041 & 0.4604 & 107.32 \\
\hline
\end{tabular}

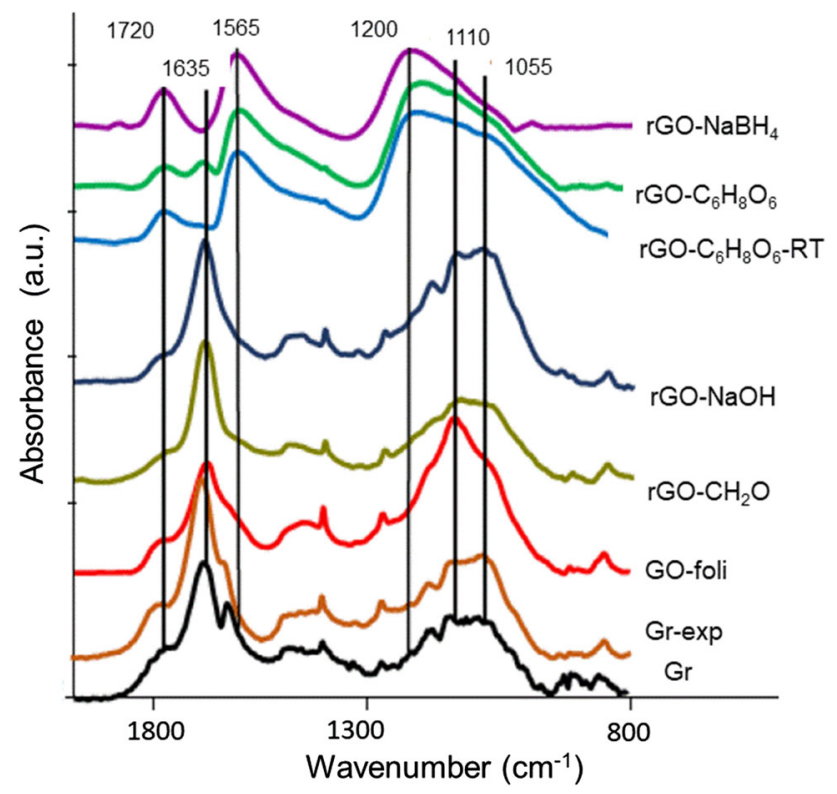

Figure 4 The FTIR spectra recorded from the investigated samples.

(near $1620 \mathrm{~cm}^{-1}$ ) take place. Similar changes can be observed for GO reduced with formaldehydes (rGO$\mathrm{CH}_{2} \mathrm{O}$ ). The $\mathrm{GO}$ reduction with other weak reduction agent-L-ascorbic acid at RT $\left(\mathrm{rGO}-\mathrm{C}_{6} \mathrm{H}_{8} \mathrm{O}_{6}-\mathrm{RT}\right)$ and (rGO- $\mathrm{C}_{6} \mathrm{H}_{8} \mathrm{O}_{6}$ ) changes the FTIR spectra due to extensive adsorption of organic molecules. Mainly the presence of the overlapped bands of aliphatic chains and hydroxyl functional groups can be observed. The reduction of GO with sodium borohydride (sample rGO-NaBH${ }_{4}$ ) completely dehydrates carbon materials (disappearance of a peak near
$1630 \mathrm{~cm}^{-1}$ ) creating anhydride structures (lactone, cyclic esters) without removing carbon-oxygen functionalities. In samples reduced using sodium borohydride and L-ascorbic acid, a decrease of alkene stretching vibration $\left(1535 \mathrm{~cm}^{-1}\right)$ and a presence of a strong amide stretching vibration $\left(1565 \mathrm{~cm}^{-1}\right)$ in contrary to GO and rGOs reduced using formaldehyde and sodium hydroxide are observed. The smallest content of water is observed in $\mathrm{rGO}-\mathrm{NaBH}_{4}$, rGO- $\mathrm{C}_{6} \mathrm{H}_{8} \mathrm{O}_{6}$ - $\mathrm{RT}$ and $\mathrm{rGO}-\mathrm{C}_{6} \mathrm{H}_{8} \mathrm{O}_{6}$ in contrary to GO, rGO-NaOH and $\mathrm{rGO}-\mathrm{CH}_{2} \mathrm{O}$.

\section{Average number of layers in graphene flakes by REELS}

The REELS spectrum of carbon nanomaterials reflects the structural features in intensity and energy loss values of reflected electrons losing their kinetic energy on valence electrons forming $\pi$ and $\pi+\sigma$ bonds $[32,33]$. The values of intensity and energy loss are characteristic for the type of bonds $\left(\mathrm{C} \mathrm{sp}^{2}\right.$ and $\mathrm{C}$ $\mathrm{sp}^{3}$ hybridizations), and content of these hybridizations at the surface (S) and in the bulk (B) varies with chemical and structural properties of carbon nanomaterials, i.e. graphite and diamond [32], single, bi-, triple-, multilayer graphene and graphene oxide [34-37]. For fitting the spectroscopic data reflecting the interaction of matter with electromagnetic radiation, the most common pseudo-Voigt profile, i.e. convolution of Lorentzian and Gaussian symmetric components, is used since Lorentzian refers to distribution of decaying oscillations and Gaussian to 
distribution of velocities leading to Doppler broadening. The REELS spectra recorded for the investigated carbon nanomaterials resulted as fitted Gaussian functions of surface and bulk $\mathrm{C} \mathrm{sp} / \mathrm{sp}^{3}$ components (Fig. S6) as reported elsewhere [5]. Results of this fitting presenting the electron kinetic energy loss values typical for surface (S) and bulk (B) $\mathrm{C} \mathrm{sp}^{2}$ and $\mathrm{C} \mathrm{sp} \mathrm{p}^{3}$ components, these components' percentage contributions and the ratio of $\mathrm{C} \mathrm{sp}{ }^{2} \mathrm{~B} /$ $\mathrm{C} \mathrm{sp}^{2} \mathrm{~S}$ are listed in Table 4. For approximating the intensity ratio of $\pi+\sigma$ energy loss peak components from $\mathrm{C} \mathrm{sp}{ }^{2} \mathrm{~B}$ bulk to $\mathrm{C} \mathrm{sp} \mathrm{s}^{2} \mathrm{~S}$ surface as a function of graphene layer in-depth profile, $z$, Eq. (2) is applied. For a single layer graphene, the ratio of $\mathrm{C} \mathrm{sp}{ }^{2} \mathrm{~B} /$ $\mathrm{C} \mathrm{sp}^{2} \mathrm{~S}$ is zero, whereas for graphite, it results from the experimental REELS spectra fitting (Fig. S6). The average number of layers, $n$, within the in-depth profile, $z$, of graphene flakes (Fig. 5) was evaluated using interlayer distances from XRD (Table 2). The values of $n$ resulting from REELS (Table 4) and XRD (Table 2) for GO and rGOs flakes are consistent, as also reported previously [5].

\section{Surface elemental content, $C s p^{2} / s p^{3}$ \\ hybridizations and oxygen groups \\ in graphene flakes}

The quantification of the surface atomic content of $\mathrm{GO}$ and rGOs was carried out from the area under $\mathrm{C}$ $1 \mathrm{~s}, \mathrm{O} 1 \mathrm{~s}, \mathrm{~N} 1 \mathrm{~s}$, Na $1 \mathrm{~s}, \mathrm{Si} 2 \mathrm{p}$ and S 2p photoelectron peaks after using Tougaard background subtraction [38]. The atomic content was evaluated from the XPS MultiQuant software [39, 40] accounting for Scofield photoionization cross sections [41], electron elastic scattering and analyzer transmission function. The results are presented in Table S2 and Fig. 6.

Samples of GO and rGO show contaminations of $\mathrm{N}, \mathrm{Na}, \mathrm{S}$ and Si (Table S2, Fig. 6a). For rGOs, the increasing content of $\mathrm{C}$ and decreasing content of $\mathrm{O}$ are observed with increasing number of layers in flakes (Fig. 6). The $\mathrm{C} 1 \mathrm{~s}$ and $\mathrm{O} 1 \mathrm{~s}$ spectra after Tougaard inelastic background subtraction [38] were fitted as suggested by Kovtun et al. [42] to pseudoVoigt functions (combination of Gauss and Lorentz asymmetric and symmetric components) using the XPSPeakfit software [43]. The C1s spectra components binding energy (BE) values for different chemical forms, i.e. $\mathrm{C} \mathrm{sp}^{2} / \mathrm{C} \mathrm{sp}{ }^{3}$ hybridizations and oxygen groups (hydroxyl $-\mathrm{C}-\mathrm{OH}$, epoxy $-\mathrm{C}-\mathrm{O}-\mathrm{C}$, carbonyl $-\mathrm{C}=\mathrm{O}$ and carboxyl $-\mathrm{C}-\mathrm{OOH}$ ), were applied as reported elsewhere for different carbon nanomaterials like nanodiamonds, graphite, carbon nanotubes, graphene oxide and graphene [42,44-48 and references within]. The vacancy defects were considered at about $283.9 \mathrm{eV}$ as suggested by Barinow et al. [48]. The $\mathrm{O} 1 \mathrm{~s}$ BE of carbon-oxygen groups was selected in the range of experimental $[5,49,50]$ and calculated values [50]. The resulting fitted spectra are shown in Fig. S7, S8. The values of C $1 \mathrm{~s}$ and $\mathrm{O} 1 \mathrm{~s}$ BEs for carbon lattice vacancies, $\mathrm{C} \mathrm{sp^{2 } /}$ $\mathrm{sp}^{3}$ hybridizations and carbon-oxygen groups resulting from the above fitting procedure shown in Table S3 and S4 are in agreement with a literature data $[5,42,44-50]$. The evaluated oxygen content resulting from $\mathrm{C} 1 \mathrm{~s}$ and $\mathrm{O} 1 \mathrm{~s}$ spectra fitting is in a reasonable agreement (Fig. S9).

Comparison of carbon-oxygen groups content is provided in Fig. 7a-b. For all carbon nanomaterials the C $1 \mathrm{~s} \mathrm{BE}$ of $\mathrm{C} \mathrm{sp}{ }^{2}$ component is $284.5 \pm 0.1 \mathrm{eV}$ (Table S3). Samples of graphite show at the surface $\mathrm{C}-\mathrm{OH}$ and $\mathrm{C}=\mathrm{O}$ groups and traces of an adsorbed water. Samples of GO and $\mathrm{rGO}$ show additionally $\mathrm{C}-$ $\mathrm{O}-\mathrm{C}$ and $\mathrm{C}-\mathrm{OOH}$ groups and a larger content of water at $\mathrm{O} 1 \mathrm{~s} \mathrm{BE}$ of $535.2 \pm 0.1 \mathrm{eV}, 536.4 \pm 0.3 \mathrm{eV}$, $538.3 \pm 0.3 \mathrm{eV}$, attributed to adsorbed water, liquid water and liquid and gas phase water (overlapping peaks), respectively, as reported elsewhere [51-54]. Reduction of GO decreases the amount of carbonoxygen groups $\mathrm{C}-\mathrm{OH}>\mathrm{C}-\mathrm{O}-\mathrm{C}>\mathrm{C}=\mathrm{O}>\mathrm{C}-\mathrm{OOH}$ and vacancy and $\mathrm{C} \mathrm{sp}^{3}$ defects (Table S3). This is observed with increasing number of graphene layers in flakes (Fig. 7a). The ratio of rGO to GO carbonoxygen groups decreasing for $\mathrm{C}-\mathrm{OH}$ and increasing for $\mathrm{C}-\mathrm{OOH}>\mathrm{C}=\mathrm{O}>\mathrm{C}-\mathrm{O}-\mathrm{C}$ accompanied by dehydration (Figs. 4, 7a, Table S4) with number of layers suggests different rate of oxygen groups reduction influencing the thickness of rGO flakes (Fig. 7b).

The dependence of number of graphene layers on the in-depth distribution of $\mathrm{C} \mathrm{sp}{ }^{3}$ defects resulting from evaluation using: (i) the first derivative of Auger C KLL spectrum [55] from which the parameter D is calculated [46] (C $\mathrm{sp}^{3}{ }_{\mathrm{C}} \mathrm{KLL}$ ) (Fig. S10), (ii) $\mathrm{C} 1 \mathrm{~s}$ spectra fitting $\left(\mathrm{C} \mathrm{sp}_{\mathrm{C}}^{3} \mathrm{~s}_{\mathrm{s}}\right)$ (Table S5), REELS spectra fitting of (iii) surface ( $\mathrm{C} \mathrm{sp}^{3}{ }_{\text {REELS-surface }}$ ) and (iv) bulk $\left(\mathrm{C} \mathrm{sp}^{3}\right.$ REELS-bulk $)$ components (Table 4 ) is provided in Fig. 8a. The GO-rGOs show surface $\mathrm{C} \mathrm{sp}^{3}$ enrichment. The content of $\mathrm{C} \mathrm{sp}^{3}$ decreases with a depth since an average information depth increases as following: REELS-surface (outer surface layer) $<\mathrm{C}$ 
Table 4 Comparison of REELS spectral parameters for the investigated GOs and rGOs resulting from the fitting of the respective spectra to Gaussian functions

\begin{tabular}{|c|c|c|c|c|c|c|c|}
\hline \multirow[t]{2}{*}{ Sample } & \multicolumn{4}{|c|}{$\pi+\sigma$ contributions $(\%)$} & \multirow{2}{*}{$\begin{array}{l}\pi+\sigma \\
\mathrm{C} \mathrm{sp}{ }^{2} \mathrm{~B} / \\
\mathrm{C} \mathrm{sp}^{2} \mathrm{~S}\end{array}$} & \multicolumn{2}{|c|}{ Number of layers, $n$} \\
\hline & $\begin{array}{l}\mathrm{C} \mathrm{sp}^{2} \mathrm{~S} \\
\mathrm{E}_{\text {loss }}=19.5 \mathrm{eV}\end{array}$ & $\begin{array}{l}\mathrm{C} \mathrm{sp}{ }^{2} \mathrm{~B} \\
\mathrm{E}_{\text {loss }}=27 \mathrm{eV}\end{array}$ & $\begin{array}{l}\mathrm{C} \mathrm{sp}{ }^{3} \mathrm{~S} \\
\mathrm{E}_{\text {loss }}=23 \mathrm{eV}\end{array}$ & $\begin{array}{l}\mathrm{C} \mathrm{sp}{ }^{3} \mathrm{~B} \\
\mathrm{E}_{\text {loss }}=33.8 \mathrm{eV}\end{array}$ & & $\begin{array}{l}\text { REELS } d \text { from } \\
\text { XRD (Table 2) }\end{array}$ & $\begin{array}{l}\text { Averaged } n \text { from XRD } \\
\text { (Table 2) and REELS }\end{array}$ \\
\hline $\begin{array}{l}\text { GO-foil- } \\
\text { fresh }\end{array}$ & 21.8 & 25.3 & 39.9 & 13.0 & 1.16 & 2.6 & 2.6 \\
\hline GO-foil & 13.0 & 33.0 & 33.2 & 20.8 & 2.54 & 6.1 & $6.5 \pm 0.4$ \\
\hline $\begin{array}{l}\mathrm{rGO}- \\
\mathrm{NaBH}_{4}\end{array}$ & 12.4 & 16.3 & 52.1 & 19.2 & 1.32 & 5.4 & $3.4 \pm 2.0$ \\
\hline $\begin{array}{l}\text { "rGO- } \\
\mathrm{N}_{2} \mathrm{H}_{4}\end{array}$ & 15.6 & 39.0 & 23.8 & 21.6 & 2.51 & 6.1 & $4.8 \pm 1.9$ \\
\hline $\begin{array}{l}\text { rGO- } \\
\mathrm{C}_{6} \mathrm{H}_{8} \mathrm{O}_{6^{-}} \\
\mathrm{RT}\end{array}$ & 15.1 & 30.4 & 33.7 & 20.8 & 2.01 & 7.3 & $5.9 \pm 1.4$ \\
\hline $\begin{array}{l}\text { rGO- } \\
\mathrm{C}_{6} \mathrm{H}_{8} \mathrm{O}_{6}\end{array}$ & 13.6 & 31.2 & 34.7 & 20.5 & 2.29 & 9.4 & $7.1 \pm 2.4$ \\
\hline $\begin{array}{l}\mathrm{rGO}- \\
\mathrm{CH}_{2} \mathrm{O}\end{array}$ & 17.2 & 31.4 & 33.6 & 17.8 & 1.83 & 8.4 & $10.1 \pm 1.7$ \\
\hline $\begin{array}{l}\text { rGO- } \\
\mathrm{NaOH}\end{array}$ & 16.2 & 32.2 & 34.8 & 16.8 & 1.99 & 9.4 & $12.4 \pm 2.1$ \\
\hline $\mathrm{Gr}$ & 18.5 & 74.7 & 6.8 & 0 & 4.04 & 29.3 & \\
\hline Gr-exp & 14.7 & 61.9 & 20.8 & 2.5 & 4.21 & 32.6 & \\
\hline
\end{tabular}

*From Ref [5]. Results calculated for electron primary energy of $2000 \mathrm{eV}$

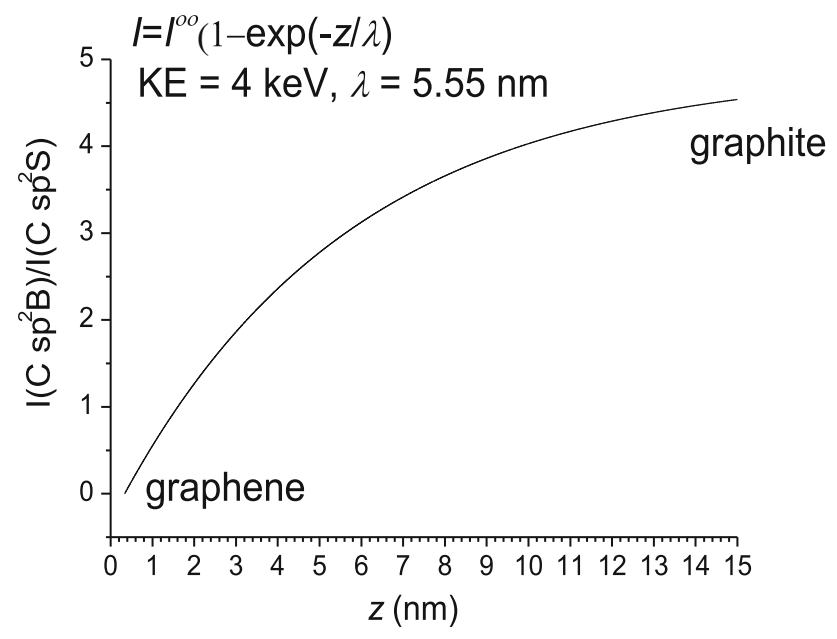

Figure 5 Dependence of $\mathrm{C} \mathrm{sp}{ }^{2} \mathrm{~B} / \mathrm{C} \mathrm{sp}^{2} \mathrm{~S}$ ratio on the penetration depth for electron signal information depth $I D(P=99 \%)$, IMFP in graphite from Shinotsuka [24] for evaluating the average number of layers resulting from REELS and Raman spectra.

KLL (1-2 layers) < REELS-bulk C 1 s (2-5 layers) (Table 1). The smallest difference between the outer layer and 1-2 layers below obtained for rGOs of the thinnest flakes indicates the most efficient penetration of a reducing agent between the layers, i.e. case of rGO-NaBH ${ }_{4}$ and $\mathrm{rGO}-\mathrm{N}_{2} \mathrm{H}_{4}$ (Fig. 8b).

\section{Influence of reducing agents on structural} and chemical properties of graphene flakes

Dependence of different physicochemical properties of rGO flakes on the number of layers is presented in Figs. 6-9. The REELS indicates that the thickness of graphene flakes in $\mathrm{GO}$ and $\mathrm{rGO}$ increases in the order of GO-foil-fresh $<$ rGO-NaBH $\mathrm{N}_{4}<\mathrm{rGO}-\mathrm{N}_{2} \mathrm{H}_{4}$ $<$ rGO-C ${ }_{6} \mathrm{H}_{8} \mathrm{O}_{6}<\mathrm{rGO}-\mathrm{CH}_{2} \mathrm{O}<\mathrm{rGO}-\mathrm{NaOH}$. This is accompanied by increasing graphitic cluster size, $L_{a}$, from $1.34 \mathrm{~nm}$ to $1.5 \mathrm{~nm}$ (Table 2) and $\mathrm{C} / \mathrm{O}$ ratio (Fig. 6), distance between defects and decreasing defect density, decreasing interlayer distance, content of $\mathrm{C} \mathrm{sp}{ }^{3}$ hybridizations and vacancy defects (Fig. 9), carbon-oxygen groups and water situated between the interstitial layers (Fig. 7, Table S3, S4). The reduction using various reductants proceeds with different rate, where oxygen group content decreases in the following order: $\mathrm{C}-\mathrm{OH}>\mathrm{C}-\mathrm{O}-\mathrm{C}>\mathrm{C}=\mathrm{O}>$ $\mathrm{C}-\mathrm{OOH}$ (Fig. 7a). The intensity and width of $D$ and 
(a)

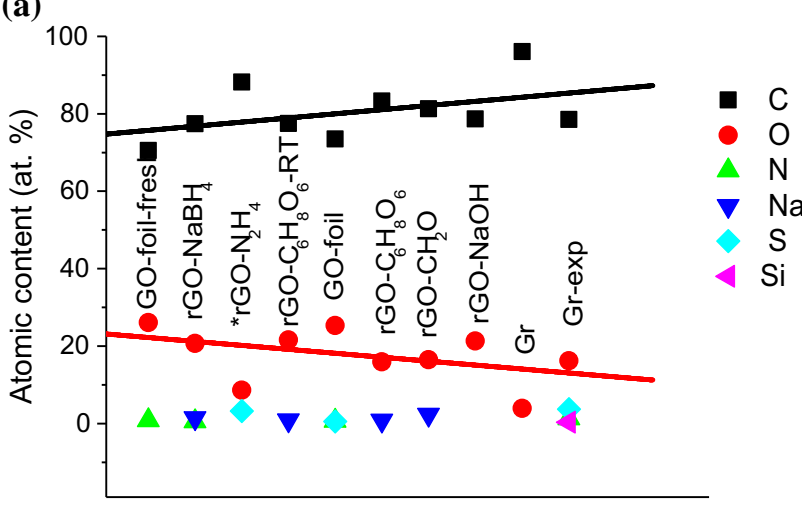

increasing number of layers

(b)

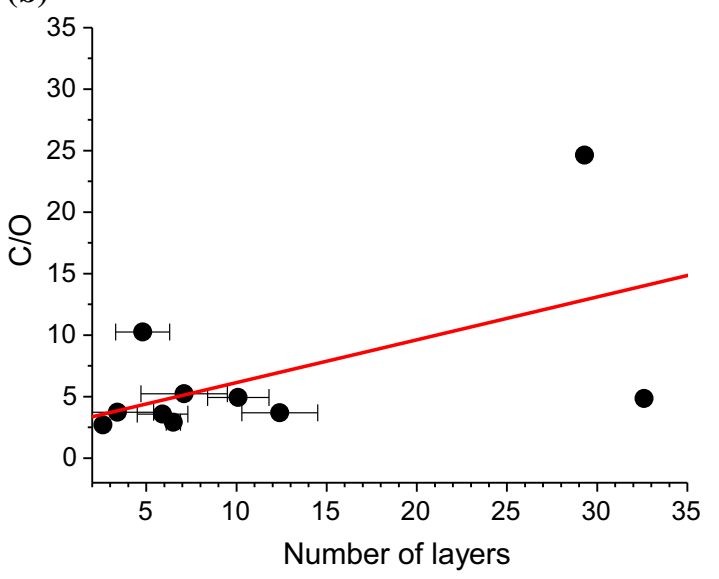

Figure 6 a Surface atomic content determined from XPS in carbon nanomaterials (Table S2) the samples are indicated in the order of increasing number of layers in graphene flakes and $\mathbf{b} \mathrm{C} / \mathrm{O}$ (Table S2) ratio as a function of the average number of graphene layers (Table 4). Notation “*” - sample from Ref [5].

$G$ modes in Raman spectra provide evidence on average distance between defects $L_{D}<3 \mathrm{~nm}$ [19]. For rGOs, the XPS results indicate decreasing density of $\mathrm{C} \mathrm{sp}{ }^{3}$ and vacancy defects with increasing number of layers in graphene flakes (Fig. 9a). The estimate of $L_{D}$ from $\mathrm{C} \mathrm{sp}{ }^{3}$ and vacancy defects (Table S3) provides for GO the value of $L_{D}<1 \mathrm{~nm}\left(\mathrm{C} \mathrm{sp}^{3}\right.$ defects) and $L_{D} \sim 15 \mathrm{~nm}$ (vacancy defects), whereas for rGOs, $L_{D} \sim 1-2 \mathrm{~nm}\left(\mathrm{C} \mathrm{sp}^{3}\right.$ defects) and 4-15 nm (vacancy defects). The oxygen content obtained from XPS (Table S2) in a range of 26.1 at.\% (GO-foil-fresh) to 8.6 at.\% $\left(\mathrm{rGO}-\mathrm{N}_{2} \mathrm{H}_{4}\right)$ provides an estimate of distance between defects of $L_{D} \sim 1 \mathrm{~nm}$ and $L_{D} \sim 3 \mathrm{~nm}$, respectively, which remains in agreement with the Raman spectroscopy data.

The modification of the flake size of rGOs, i.e. height and diameter, depends on the applied (a)

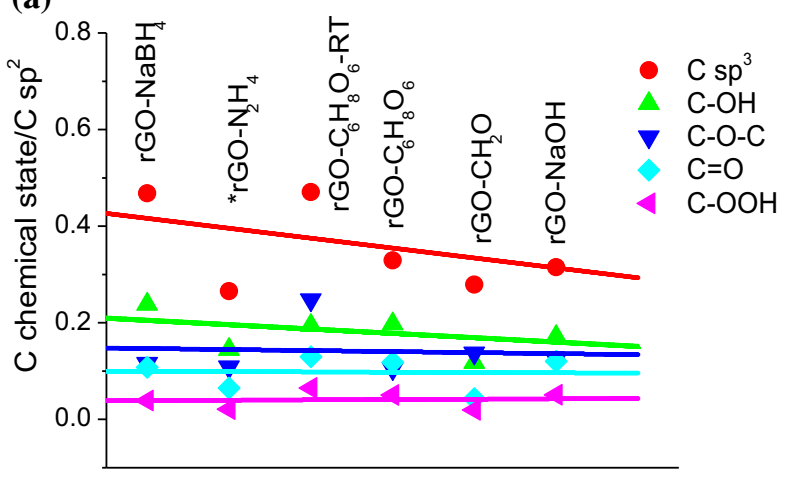

increasing number of layers

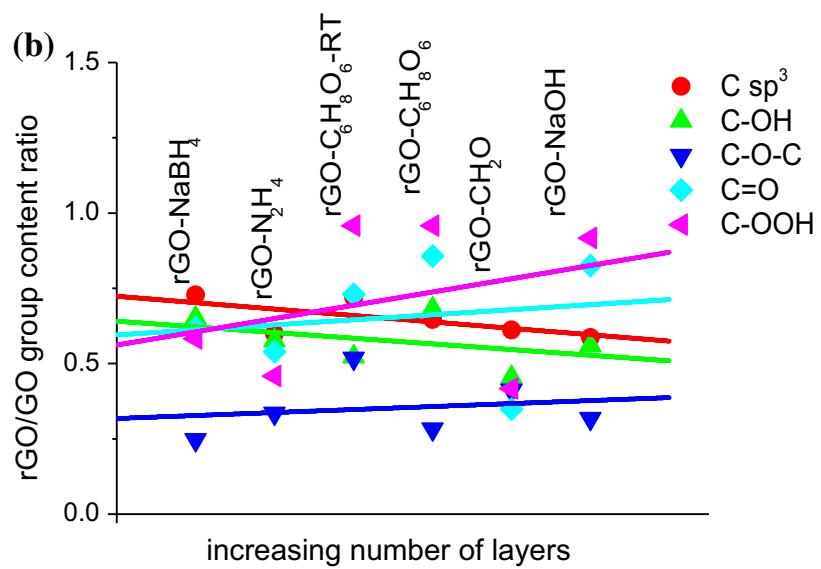

Figure 7 a Surface atomic content of $\mathrm{C} \mathrm{sp}^{3}$ hybridizations,

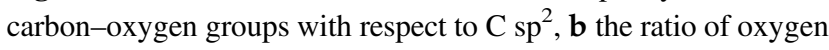
group content in rGOs to GO (Table S3); in $\mathbf{a}-\mathbf{b}$ the rGOs are indicated in the order of increasing number of layers in graphene flakes.

reductants (Fig. 9b). The rGO-NaBH 4 of the thinnest flakes (Table 4) and flake diameter similar to GO (Table 2) shows the largest number of surface carbon-oxygen groups and vacancy defects of larger content than in GO (Table S3, Fig. 7a, Fig. 9a). Also, no water is present between the interstitial sites (Fig. 4) and the ratio of rGO to GO group content decreases in the following order: $\mathrm{C}-\mathrm{OH}>\mathrm{C}$ $\mathrm{OOH}>\mathrm{C}=\mathrm{O}>\mathrm{C}-\mathrm{O}-\mathrm{C}$ (Fig. $7 \mathrm{~b}$ ) due to a mechanism of $\mathrm{NaBH}_{4}$ reduction converting $\mathrm{C}=\mathrm{O}$ and $\mathrm{C}-\mathrm{OOH}$ to $\mathrm{C}-\mathrm{OH}$ groups as proposed by Samulski [56]. The rGO- $\mathrm{N}_{2} \mathrm{H}_{4}, \mathrm{rGO}-\mathrm{C}_{6} \mathrm{H}_{8} \mathrm{O}_{6}, \mathrm{rGO}-\mathrm{NaOH}, \mathrm{rGO}-$ $\mathrm{CH}_{2} \mathrm{O}$ of thicker flakes and smaller diameters than GO exhibit a similar content of vacancy defects than

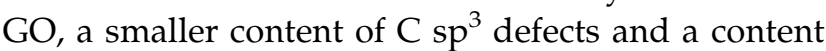
of oxygen groups decreasing in an order: $\mathrm{C}-\mathrm{OOH}>$ $\mathrm{C}=\mathrm{O}>\mathrm{C}-\mathrm{OH}>\mathrm{C}-\mathrm{O}-\mathrm{C}$. The binding energies for carbon-oxygen groups in graphene and defected 
graphene, where edges may be considered as defected graphene, do not vary distinctly [57]. However, a predominant rate of reduction between the interstitial site over that in plane results in thin flakes of a large diameter, whereas a higher rate of reduction in plane leads to smaller diameter flakes of larger number of layers. The reduction of GO at RT conditions in contrary to boiling conditions (e.g. exemplary rGO$\mathrm{C}_{6} \mathrm{H}_{8} \mathrm{O}_{6}$ - $\mathrm{RT}$ sample) results in a larger number of $\mathrm{C}$ $\mathrm{sp}^{3}$ and vacancy defects, carbon-oxygen groups, interstitial water and smaller average number of layer in flakes. The boiling reduction conditions lead to reparation of the vacancy defects and provide a higher reduction rate between the interstitial sites.
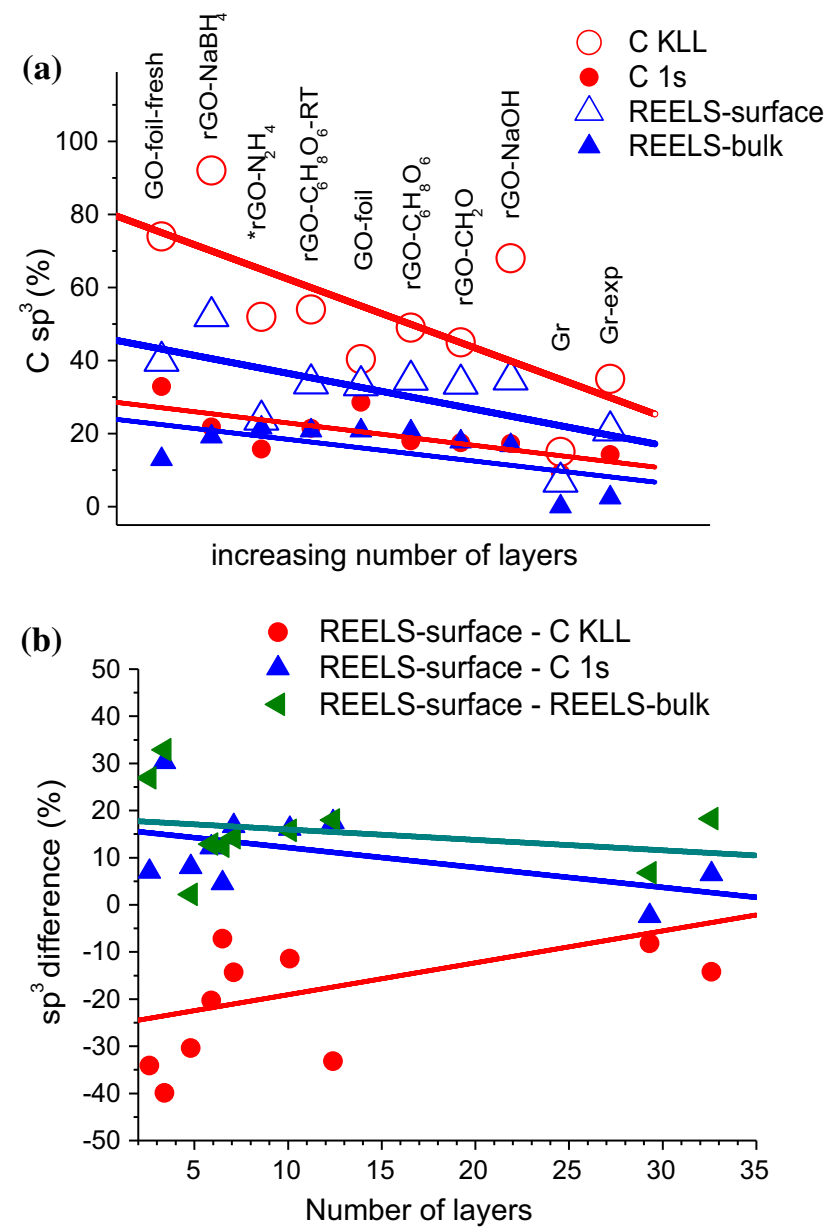

Figure 8 Comparison of a $\mathrm{C} \mathrm{sp}^{3}$ content resulting from Auger $\mathrm{C}$ KLL spectra parameter D evaluation (Table S5), C 1 s spectra fitting (Table S3) and REELS spectra fitting (Table 4) the samples are indicated in the order of increasing number of layers and b difference in $\mathrm{C} \mathrm{sp}^{3}$ percent resulting from C KLL, C $1 \mathrm{~s}$ and REELS-surface and REELS-bulk components. Notation “*”sample from Ref [5].
Aging of GO (sample GO-foil-fresh and GO-foil) provides a larger number of layers in flakes, which could be influenced by additional oxidation and adsorption of water leading to graphene layers stacking.

\section{Summary of results and conclusions}

The bulk and surface properties of GO prepared from graphite using the modified Hummers method and rGOs obtained from this initial GO using a range of
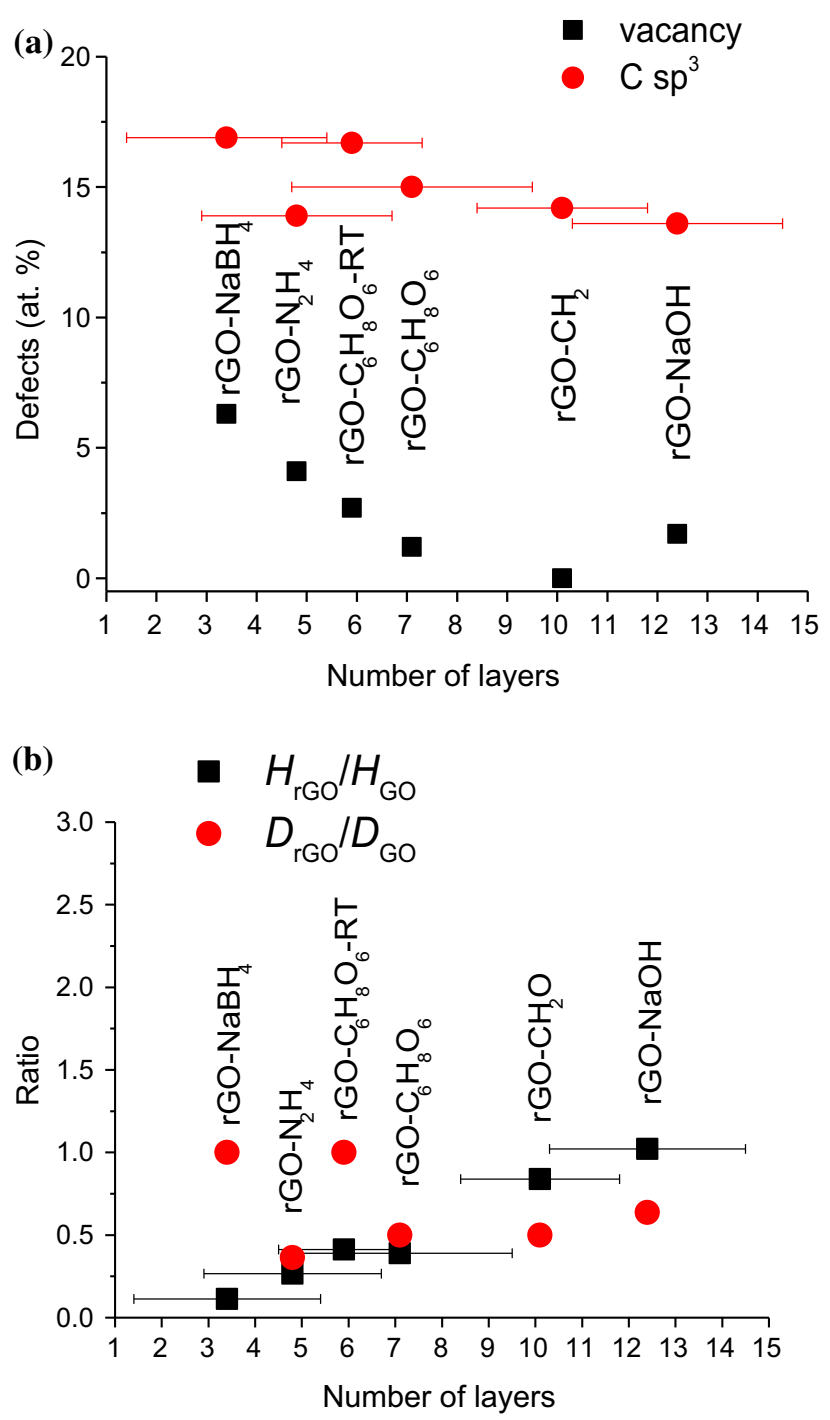

Figure 9 Dependence of a the atomic percent of vacancy and $\mathrm{C}$ $\mathrm{sp}^{3}$ defects (Table S3) obtained from XPS spectra and $\mathbf{b}$ ratio of height and diameter values of rGOs to GO flakes (Table 2) on average number of layers in graphene flakes obtained from XRD and REELS (Table 4). 
reducing agents were characterized by applying a set of complementary methods. The dependence of rGOs chemical and structural properties on the preparation procedures applying different reductants was investigated. Novelty and significance of these study rely on: (i) investigating the effect of few reducing agents like conventional and "green" reductants in similar conditions, (ii) characterizing GO and rGOs structural and chemical bulk and surface properties, (iii) providing correlation between rGOs bulk and surface properties due to the applied reductants, (iv) applying various complementary methods of analysis such as XRD, EDX, HR-TEM, PEELS, FTIR, Raman spectroscopy, REELS, XPS and XAES, (v) confirming reliability of different methods for evaluating the selected physicochemical properties.

The GO and rGOs showed different interlayer distances in the range of ca. $0.446-0.345 \mathrm{~nm}$ with the largest interlayer distance for GO $(0.721 \mathrm{~nm})$. The GO and GO flakes of different size, i.e. diameter and height containing various average number of layers, were obtained. The number of layers in flakes resulting from XRD and REELS analyses was in agreement. For rGOs, the number of layers in flakes increased in the following order: $\mathrm{NaBH}_{4}<\mathrm{N}_{2} \mathrm{H}_{4}$ $<\mathrm{C}_{6} \mathrm{H}_{8} \mathrm{O}_{6}-\mathrm{RT}<\mathrm{C}_{6} \mathrm{H}_{8} \mathrm{O}_{6}<\mathrm{CH}_{2} \mathrm{O}<\mathrm{NaOH}$ from $3.4 \pm 2 \mathrm{~nm}$ to $12.4 \pm 2.1 \mathrm{~nm}$. This was accompanied by increasing graphitic cluster size from $1.34 \mathrm{~nm}$ to $1.5 \mathrm{~nm}$, distance between defects and decreasing defect density. The Raman and XPS data provided in GO-rGOs a consistent value of distance between defects, $L_{D}$, from 1 to $3 \mathrm{~nm}$. The content of oxygen groups decreased in the order of $\mathrm{C}-\mathrm{OH}>\mathrm{C}-\mathrm{O}-$ $\mathrm{C}>\mathrm{C}=\mathrm{O}>\mathrm{C}-\mathrm{OOH}$ and the ratio of these oxygen groups in rGO to $\mathrm{GO}$ showed decrease for $\mathrm{C}-\mathrm{OH}$ groups and increase for $\mathrm{C}-\mathrm{OOH}>\mathrm{C}=\mathrm{O}>\mathrm{C}-\mathrm{O}-\mathrm{C}$ groups. This provides an evidence on the importance of $\mathrm{C}-\mathrm{OH}$ groups present in planes and edges to obtain thin graphene flakes. The GO showed the most inhomogeneous distribution of oxygen groups and C $\mathrm{sp}^{3}$ hybridizations at the surface and in the bulk. In contrary to GO, the rGOs obtained using various reductants resulted in decreasing differences between in-depth distribution of the $\mathrm{C} \mathrm{sp}^{3}$ and carbon-oxygen groups with increasing number of layers. The applied reductants provided rates of reduction between the interstitial sites, which are different from the rates in the planes. The thinnest flakes were obtained for $\mathrm{rGO}-\mathrm{NaBH}_{4}$, characterized by the largest density of vacancy and $\mathrm{C} \mathrm{sp}^{3}$ defects, content of $\mathrm{C}-\mathrm{OH}$ group, inhomogeneous in-depth distribution of $\mathrm{C} \mathrm{sp}{ }^{3}$, where the reduction proceeded predominantly between the interstitial sites.

\section{Acknowledgement}

The authors (B.L., L.K, J.T.) acknowledge the support of the bilateral project between the Polish Academy of Sciences and the Hungarian Academy of Sciences. The authors (B.L., N.R., L.K.) acknowledge the support of the Horizon 2020 MSCA-COFUND agreement No. 711859 and the financial resources for science in the years 2017-2021 awarded for the implementation of an international co-financed project $(3549 / \mathrm{H} 2020 /$ COFUND/2016/2). The author (J.T.) acknowledges the support by the European Regional Development Fund and Hungary in the frame of the project GINOP-2.2.1-15-2016-00012. The author (G.T.) acknowledges the support by the National Science Centre Poland for financial support (Grant "MINIATURA" No. 2017/01/X/ST5/01248). The author A. M. thanks the National Centre for Research and Development for support of the project LIDER/33/ 0117/L-9/17/NCBR/2018. The author L. S. would like to thank for the support of the project NCBiR (2018-2012) POIR.01.01.01-00-0802/17-00 (Polski Bazalt S.A.).

\section{Compliance with ethical standards}

Conflict of interest The authors declare that they have no conflict of interest.

Electronic supplementary material: The online version of this article (https://doi.org/10.1007/s108 53-020-05461-1) contains supplementary material, which is available to authorized users.

Open Access This article is licensed under a Creative Commons Attribution 4.0 International License, which permits use, sharing, adaptation, distribution and reproduction in any medium or format, as long as you give appropriate credit to the original author(s) and the source, provide a link to the Creative Commons licence, and indicate if changes were made. The images or other third party material in this article are included in the article's Creative Commons licence, unless indicated otherwise in a credit line to the material. If material is not included in the article's Creative Commons licence and your intended use is 
not permitted by statutory regulation or exceeds the permitted use, you will need to obtain permission directly from the copyright holder. To view a copy of this licence, visit http://creativecommons.org/licen ses/by/4.0/.

\section{References}

[1] Pei S, Cheng H-M (2012) The reduction of graphene oxide. Carbon 50:3210-3228

[2] Dreyer DR, Park S, Bielawski CW, Ruoff RS (2012) The chemistry of graphene oxide. Chem Soc Rev 39:228-240

[3] Chua CK, Pumera M (2014) Chemical reduction of graphene oxide: a synthetic chemistry viewpoint. Chem Soc Rev 43:291-312

[4] Obata S, Tanaka H, Saiki E (2013) Electrical and spectroscopic investigations on the reduction mechanism of graphene oxide. Carbon 55:126-132

[5] Stobinski L, Lesiak B, Malolepszy A, Mazurkiewicz M, Mierzwa B, Zemek J, Jiricek P, Bieloshapka I (2014) Graphene oxide and reduced graphene oxide studied by the XRD, TEM and electron spectroscopy methods. J Electron Spectros Re Phenom 195:145-154

[6] Ren P-G, Yan D-X, Ji X, Che T, Li Z-M (2011) Temperature dependence of graphene oxide reduced by hydrazine hydrate. Nanotechnology 22:055705-055708

[7] Guo H, Peng M, Zhu Z, Sun L (2013) Preparation of reduced graphene oxide by infrared irradiation induced photothermal reduction. Nanoscale 5:9040-9048

[8] Malard LM, Pimenta MA, Dresselhaus G, Dresselhaus MS (2009) Raman spectroscopy in graphene. Phys Rep 473:51-87

[9] Niyogi S, Bekyarova E, Itkis ME, Zhang H, Shepperd K, Hicks L, Sprinkle M, Berger C, Lau CN, de Heer WA, Conrad EH, Haddon RC (2010) Spectroscopy of covalently functionalised graphene. Nano Lett 10:4061-4066

[10] Qi Z, Zhu X, Jin H, Zhang T, Kong X, Ruoff RS, Qiao Z, Ji $H$ (2018) Rapid identification of the layer number of largearea-graphene on copper. Chem Matter 30:2067-2073

[11] Szirmai P, Márkus BG, Chacón-Torres JC, Eckerlein P, Edelthalhammer K, Englert JM, Mundloch U, Hirsch A, Hauke F, Náfrádi B, Forró L, Kramberger C, Pichler T, Simon F (2019) Characterizing the maximum number of layers in chemically exfoliated graphene. Scientific Reports 9:19480-19510

[12] Ferrari AC, Robertson J (2000) Interpretation of Raman spectra of disordered and amorphous carbon. Phys Rev B 61(20):14095-14107
[13] Tunistra F, Koenig JL (1970) Raman spectrum of graphite. J Chem Phys 53:1126-1130

[14] Lan Y, Zondode M, Deng H, Yan J-A, Ndaw M, Lisfi A, Wang Ch, Pan Y-L (2018) Basic Concepts and recent advances of crystallographic orientation determination of graphene by Raman spectroscopy. Crystals 8:375-428

[15] Venezuela P, Lazzeri M, Mauri F (2011) Theory of doubleresonant Raman spectra in graphene: Intensity and lineshape of defect-induced and two-phonon bands. Phys Rev B 84:035433-035512

[16] Casiraghi C, Pisana S, Novoselov KS, Geim AK, Ferrari AC (2007) Raman fingerprint of charged impurities in graphene. Appl Phys Lett 91:233108-3p

[17] Eckmann A, Felten A, Mishchenko A, Britnell L, Krupke R, Novoselov KS, Casiraghi C (2012) Probing nature of defects in graphene by Raman spectroscopy. Nano Lett 12:3925-3930

[18] Lucchese MM, Stavale F, Martin Ferreire EH, Vilani C, Moutinho MVO, Capaz RB, Achete CA, Jorio A (2010) Quantifying ion-induced defects and Raman relaxation length in graphene. Carbon 48:1592-1597

[19] Cançado LG, Jorio A, Martins Ferreira EH, Sravale F, Achete CA, Capaz RB, Moutinho MVO, Lombardo A, Kulmala TS, Ferrari AC (2011) Quantifying defects in graphene via Raman Spectroscopy at different excitation energies. Nano Lett 11:3190-3196

[20] Jablonski A, Powell CJ (2004) Information depth for elasticpeak electron spectroscopy. Surf Sci 551:106-124

[21] Jablonski A, Powell CJ (2009) Practical expressions for the mean escape depth, the information depth, and the effective attenuation length in Auger-electron spectroscopy and X-ray photoelectron spectroscopy. J Vac Sci Technol A 27:253-261

[22] Standard E 673-01, Annual Book of ASTM Standards 2002, ASTM International, West Conshohocken, PA, 2002, vol 3.06 , p. 755.

[23] ISO 18115, Surface Chemical Analysis - Vocabulary, International Organization for Standarization, Geneva, 2001.

[24] Shinotsuka H, Tanuma S, Powell CJ, Penn DR (2015) Calculations of electron inelastic mean free paths. X. Data for 41 elemental solids over the $50 \mathrm{eV}$ to $200 \mathrm{keV}$ range with the relativistic full Penn algorithm. Surf Interface Anal 47:871-888

[25] Xu M, Fujita D, Gao J, Hanagata N (2010) Auger electron spectroscopy: A rational method for determining thickness of graphene films. ACS Nano 4:2937-2945

[26] Jablonski A, Zemek J (2009) Overlayer thickness determination by XPS using the multiline approach. Surf Interface Anal 41:193-204 
[27] Hummers WS, Offeman RE (1958) Preparation of graphitic oxide. J Am Chem Soc 80:311-336

[28] Kövér L, Varga D, Cserny I, Tóth J, Tökési K (1992) Some applications of high-energy, high-resolution Auger-electron spectroscopy using Bremsstrahlung radiation. Surf Interface Anal 19:9-15

[29] Pan Q, Chung C-C, He N, Jones JN, Gao W (2016) Accelerated thermal decomposition of graphene oxide films in air via in situ X-ray diffraction analysis. J Phys Chem C 120:14984-14990

[30] Yuan R, Yuan J, Wu Y, Chen L, Zhou H, Chen J (2017) Efficient synthesis of graphene oxide and the mechanisms of oxidation and exfoliation. Appl Surf Sci 416:868-877

[31] Rezania B, Severin N, Talyzin AV, Rabe JP (2014) Hydration of bilayered graphene oxide. Nano Lett 14(7):3993-3998

[32] Calliari L, Fanczenko S, Filippi M (2007) Plasmon features in electron energy loss spectra from carbon materials. Carbon 45:1410-1418

[33] Eberlein JT, Bangert U, Nair RR, Jones R, Gass M, Bleloch AL, Novoselov AS, Geim A, Briddon PR (2008) Plasmon spectroscopy of free-standing graphene films. Phys Rev B: Condens Matter 77:233406-233414

[34] Johari P, Shenoy VB (2011) Modulating optical properties of graphene oxide: Role of prominent functional groups. ACS Nano 5:7640-7647

[35] Xu Z, Bando Y, Liu L, Wang W, Bai X, Golberg D (2011) Electrical conductivity, chemistry, and bonding alternations under graphene oxide to graphene transition as revealed by in situ TEM. ACS Nano 5:4401-4406

[36] Mkhoyan KA, Contryman AW, Silcox J, Stewart DA, Eda G, Mattevi C, Miller S, Chhowalla M (2009) Atomic and electronic structure of graphene-oxide. Nano Lett 9:1058-1063

[37] Gass MH, Bangert U, Bleloch AL, Wang P, Nair RR, Geim AK (2008) Free-standing graphene at atomic resolution. Nature Nanotechnol 3:676-681

[38] Touggard S, Background analysis of XPS/AES QUASES Simple Backgrounds, ver. 2.2, 1999-2001 Tougaard Inc.

[39] Mohai M (2004) MultiQuant XPS multimodel XPS quantification software. Surf Interface Anal 36:828-832

[40] Mohai M, Multimodel of X-ray photoelectron spectroscopy quantification program for 32-bit Windows, XPSMuliQuant, ver. 7, 1999-2001.

[41] Scofield H (1976) Hartree-Slater Subshell Photoionization Cross-sections at 1254 and $1487 \mathrm{eV}$. J Electron Spectrosc Relat Phenom 8:129-137

[42] Kovtun A, Jones D, Dell'Elce S, Treossi E, Liscio A, Palermo V (2019) Accurate chemical analysis of oxygenated graphene-based materials using X-ray photoelectron spectroscopy. Carbon 143:268-275

[43] Kwok RWM, XPS peak fitting program for WIN95/98 XPSPEAK, ver. 4.1, Department of Chemistry, The Chinese University of Hong Kong, XPSPEAK4.1.

[44] Estrade-Szwarckopf (2004) XPS photoemission in carbonaceous materials: A "defect" peak beside the graphitic asymmetric peak. Carbon 42:1713-1721

[45] Butenko YV, Krishnamurthy S, Chakraborty AK, Kuznetsov VL, Dhanak VR, Hunt MC, Šiller L (2005) Photoemission study of onionlike carbons produced by annealing nanodiamonds. Phys Rev B 71:075420-10p

[46] Lesiak B, Kövér L, Tóth J, Zemek J, Jiricek P, Kromka A, Rangam N (2018) C sp $/ \mathrm{sp}^{3}$ hybridisations in carbon nanomaterials - XPS and (X)AES study. Appl Surf Sci 452:223-231

[47] Lesiak B, Stobinski L, Malolepszy A, Mazurkiewicz M, Kövér L, Tóth J (2014) Preparation of graphene oxide and characterisation using electron spectroscopy. J Electron Spectrosc Rel Phenom 193:92-99

[48] Barinov A, Malcioglu OB, Fabris S, Gregoratti ST, Dalmiglio L, Kiskinova M (2009) Initial stages of oxidation of graphitic surfaces: Photoemission study and density functional theory calculations. J Phys Chem C 113:9009-9013

[49] Shim SH, Kim KT, Lee JU, Jo WH (2012) Facile method to functionalize graphene oxide and its application to poly(ethylene terephthalate)/graphene composite. ACS Appl Mater Interfaces 4:4184-4191

[50] Fujimoto A, Yamada Y, Koinuma M, Sata S (2016) Origins of $\mathrm{sp}^{3} \mathrm{C}$ peaks in $\mathrm{C}_{1 \mathrm{~s}} \mathrm{X}$-ray photoelectron spectra of carbon materials. Anal Chem 88:6110-6114

[51] Yanga Sh, Li L, Xiao T, Zheng D, Zhang Y (2016) Role of surface chemistry in modified ACF (activated carbon fiber)catalyzed peroxymonosulfate oxidation. Appl Surf Sci 383:142-150

[52] Hong S, Deng Sh, Yao X, Wang B, Wang Y, Huang J, Yu G (2016) Bromate removal from water by polypyrrole tailored activated carbon. J Col Interface Sci 467:10-16

[53] Winter B, Aziz EF, Hergenhahn U, Faubel M, Hertel IV (2007) Hydrogen bonds in liquid water studied by electron spectroscopy. J Chem Phys 126:124504-124506

[54] Yamamoto S, Bluhm H, Andersson K, Ketteler G, Ogasawara H, Salmeron M, Nilsson A (2008) In situ X-ray photoelectron spectroscopy studies of water on metals and oxides at ambient conditions. J Phys: Condend Matter 20:184025-14p

[55] Lascovich C, Scaglione S (1994) Comparison among XAES, PEELS and XPS techniques for evaluation of Sp2 percentage in a-C:H. Appl Surf Sci 78:17-23 
[56] Si Y-C, Samulski T (2008) Synthesis of water soluble graphene. Nano Lett 8(6):1679-1682

[57] Susi T, Kaukonen M, Havu P, Ljungberg MP, Ayala P, Kauppinen EI (2014) Core level binding energies of functionalized and defective graphene. Beilstein J Nanotechnol 5:121-132
Publisher's Note Springer Nature remains neutral with regard to jurisdictional claims in published maps and institutional affiliations. 